\title{
La tumba colectiva de El Hundido (Monasterio de Rodilla, Burgos) y su ritual funerario durante el Neolítico Final y el Calcolítico
}

\author{
The collective burial of El Hundido (Monasterio de Rodilla, Burgos) and its funerary \\ ritual during the Late Neolithic and the Chalcolithic
}

\author{
Carmen Alonso Fernández (*)
}

\section{RESUMEN}

Las manifestaciones funerarias documentadas en El Hundido pertenecientes al Neolítico Final y Calcolítico aportan interesantes novedades al conocimiento de los rituales funerarios del inicio de la Edad de los Metales en la Península Ibérica y de las conexiones culturales entre la Meseta y la cuenca alta y media del Valle del Ebro. La tumba colectiva, que acogió a casi un centenar de individuos, es un excepcional ejemplo de monumento funerario tanto por su estructura como por el complejo ritual en ella practicado, que culminó con su destrucción premeditada mediante cremación.

\begin{abstract}
The Late Neolithic and Chalcolithic burials documented at the site of El Hundido provide interesting new information concerning funerary rituals at the beginning of the Age of Metals in Iberia and the cultural connections between the Meseta and the upper and middle Ebro Valley. The collective burial of nearly a hundred individuals is an exceptional funerary monument in terms of both its structure and its complex ritual practices. These culminated in the deliberate destruction of the monument by fire.
\end{abstract}

Palabras clave: Arqueología de la muerte; Radiocarbono; Ajuar; Paleoantropología; Clausura por fuego; Península Ibérica.

(*) CRONOS SC, Centro Europeo de Empresas e Innovación, Módulo 3. Aeropuerto de Burgos. 09007 Burgos. Correo e.: ca@cronossc.es

Recibido: 13-I-2014; aceptado: 12-III-2014.
Key words: Mortuary archaeology; Radiocarbon; Grave goods; Paleoanthropology; Closure by burning; Iberia.

\section{CONTEXTO GEOGRÁFICO Y ARQUEOLÓGICO DEL YACIMIENTO}

El yacimiento El Hundido se localiza en el municipio burgalés de Monasterio de Rodilla, en la comarca de La Bureba, una zona de media montaña perteneciente a la unidad estructural de la Depresión del Duero, en la línea de ruptura entre las cuencas hidrográficas del Duero y del Ebro (Fig. 1). La morfología del paisaje está representada por un páramo elevado entre cuyas plataformas destaca la denominada Alto de Rodilla, donde se extiende un extenso yacimiento en cuyo borde meridional se localiza este enclave.

Las ocupaciones de la Edad del Hierro y romana representan la principal impronta arqueológica del Alto de Rodilla, en correspondencia con la ciudad autrigona posteriormente romanizada de Tritium Autrigonum. Sin embargo, destacamos en el borde meridional de la plataforma dos tumbas individuales neolíticas en fosas situadas muy cerca de El Hundido, una de ellas portadora de un interesante ajuar (Alonso y Jiménez, e.p.). El Hundido es en esencia una tumba colectiva calcolítica donde más tarde, a mediados del III milenio cal $\mathrm{BC}$, cuando todavía era reconocible, 


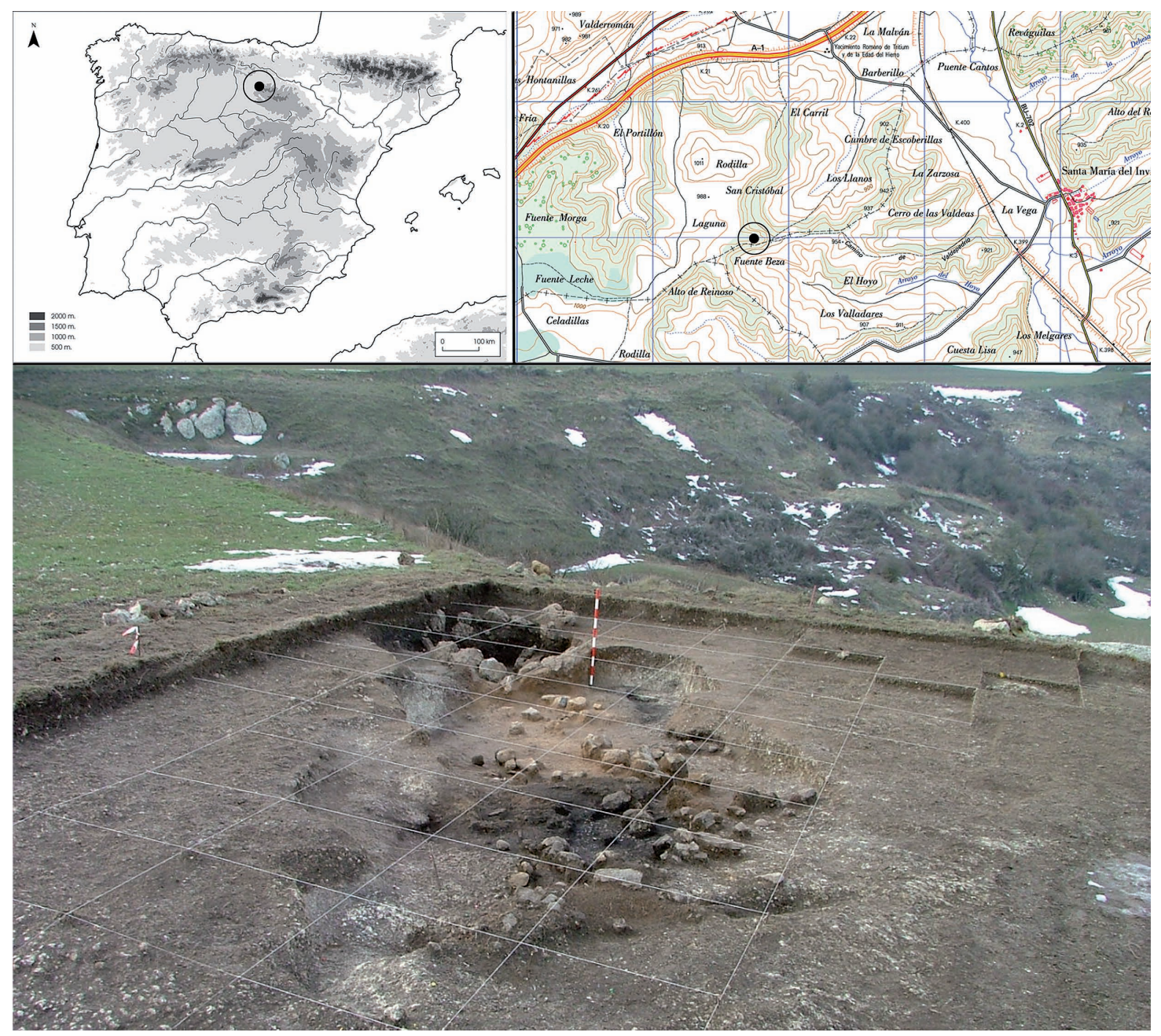

Fig. 1. Localización del yacimiento El Hundido (Monasterio de Rodilla, Burgos). El espigón de páramo del emplazamiento cuenta con una destacada posición topográfica y amplio dominio visual del territorio. MTN 1:25.000 hoja 201-I (Monasterio de Rodilla).

fueron practicados tres enterramientos intrusivos campaniformes (Alonso 2013).

La tumba colectiva ejemplifica una forma de enterramiento utilizado durante el Neolítico Final-Calcolítico, en el marco de un ritual que será abandonado a finales de este último periodo en beneficio del enterramiento individual. Es una tumba monumental de carácter no megalítico clausurada mediante fuego, en la que el carácter colectivo es su seña de identidad. Ambos aspectos se conjugan en el ritual utilizado en la Península Ibérica (Rojo y Kunst 2002) y en otros ámbitos europeos occidentales (Joussaume y Tarrête 2010; Meller 2013) en el mismo marco cronológico, que se manifiestan con un variado elenco de tipologías constructivas.

\section{CONSTRUCCIÓN, USO Y CLAUSURA DE LA TUMBA COLECTIVA}

\subsection{Elección del emplazamiento y fase de construcción}

El Hundido se localiza en un pequeño espigón de páramo de unos $1.130 \mathrm{~m}^{2}$ de superficie integrado 
en la amplia plataforma de Alto de Rodilla, concretamente en su borde suroriental, a $986 \mathrm{~m}$ de altitud (42 26' 26"N-3 ${ }^{\circ} 27^{\prime}$ '59”W, ETRS89). Tiene una destacada posición topográfica y un amplio control visual en todas las direcciones excepto hacia el oeste, donde se desarrolla la paramera. Desde su emplazamiento se domina un amplio territorio, por lo que la tumba colectiva era manifiestamente identificable en el paisaje tanto desde la vega como desde las plataformas de páramo circundantes. Se acomoda en la zona más elevada del relieve, si bien ocupa una pequeña depresión del terreno conformada por una grieta natural abierta en el sustrato rocoso calizo, de orientación noroeste-sureste.

Elegida la grieta natural como lugar de emplazamiento, se procedió a la construcción de la tumba (Fig. 2A). Para ello se entallaron los perfiles naturales, particularmente en el corredor, en las paredes oriental y meridional de la zona central de la cámara y posiblemente también el suelo, aunque en esencia se conservó la planta polilobulada del relieve original (Fig. 2B). Como resultado, se consiguió una superficie con orientación noroeste-sureste de planta irregular y profundidad variable, de unos $11 \mathrm{~m}$ de longitud y 4 $\mathrm{m}$ de anchura máxima.

El ámbito septentrional es el más profundo, coincidiendo con el entallado en la roca, donde se sitúa lo que podríamos denominar la cámara principal (A) y en cuyo extremo fue construido un pequeño corredor. En la zona meridional (B) la grieta se conservó en su estado primigenio, presentando un desarrollo más irregular y estrechándose progresivamente. La división de ambos espacios no es únicamente de carácter morfoestructural, sino que también obedece a una importante diferenciación de tipo ritual (Fig. 3).

Ambas zonas tienen una superficie muy similar: unos $6 \mathrm{~m}^{2}$. La profundidad en la septentrional (A) alcanza los $66 \mathrm{~cm}$. En la meridional (B), donde únicamente la zona central y más profunda fue utilizada con carácter funerario, es de 20-45 $\mathrm{cm}$. No se observan acondicionamientos previos en el suelo más allá del mencionado entallado, de modo que los inhumados fueron depositados directamente sobre el sustrato rocoso.

Tras el acondicionamiento de la superficie, en los flancos de la cámara septentrional (A) se construyeron dos muros longitudinales de piedra caliza procedente del entorno inmediato. Sus restos aparecieron durante la excavación arqueológica
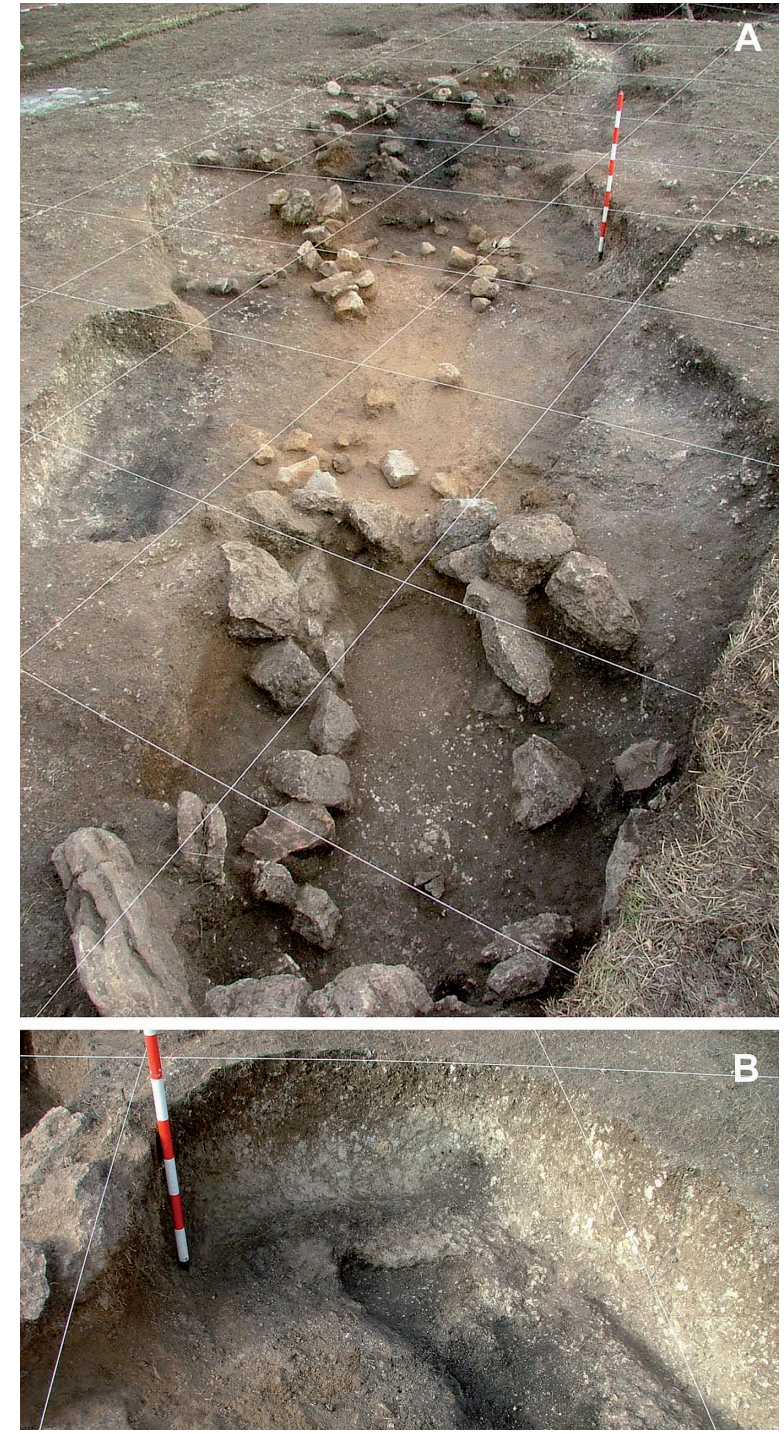

Fig. 2. El Hundido (Monasterio de Rodilla, Burgos), tumba colectiva. A. Vista general tras su excavación. En primer plano, corredor modificado en cista campaniforme; B. La grieta natural seleccionada para la construcción de la tumba fue entallada con el fin de regularizar su superficie.

en forma de un conglomerado de hidróxido de cal compactado de $55 \mathrm{~cm}$ de anchura y hasta 32 $\mathrm{cm}$ de potencia (Fig. 4). En el extremo norte se construyó un pequeño corredor que daba acceso a la cámara, coincidiendo con la zona más profunda de la grieta. Es un espacio rectangular con orientación noroeste-sureste de 2,5 m de longitud, $1,7 \mathrm{~m}$ de anchura y $50 \mathrm{~cm}$ de profundidad máxima. Los flancos fueron revestidos por piedras de hasta 68 

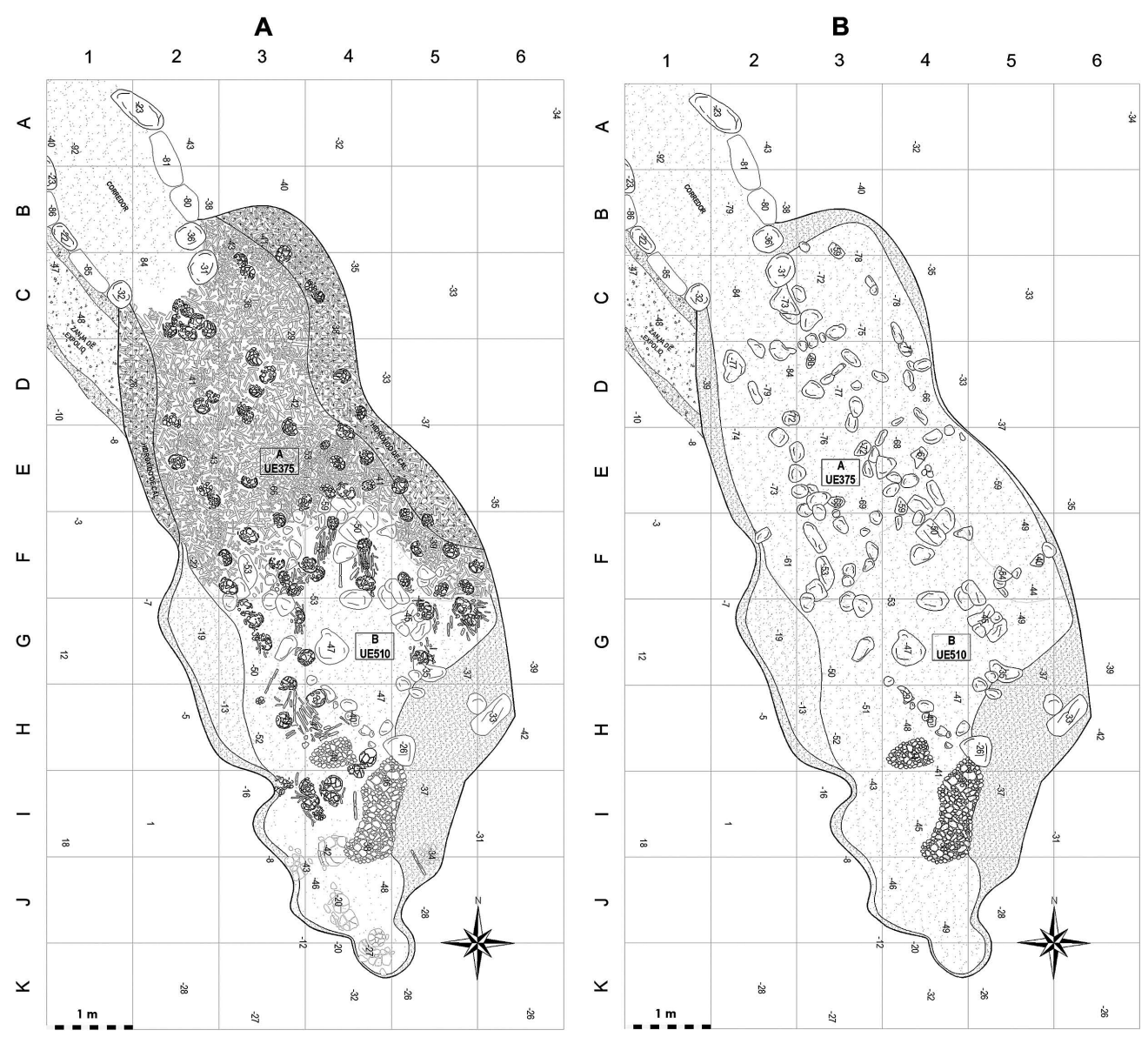

Fig. 3. El Hundido (Monasterio de Rodilla, Burgos), plano de la tumba colectiva: A. durante el proceso de excavación arqueológica; B. una vez concluida la excavación.

cm de altura, sin superposición, contribuyendo a aumentar la amplitud del corredor al superar la altura de los perfiles de la grieta. Posteriormente, algunas fueron reutilizadas para la construcción de una cista funeraria campaniforme intrusiva, por lo que únicamente fueron encontradas en posición primaria siete, aunque se aprecian con claridad las huellas en negativo que dejaron las sustraídas.

$\mathrm{Ni}$ en el corredor ni en la cámara se han documentado evidencias claras de la cubrición de la tumba. Pudo ser de material ligero de tipo vegetal, al menos en la zona meridional (B), ya que la ausencia de conglomerado de hidróxido de cal indica que no debió contar con refuerzos calizos. Además, es el único ámbito donde han aparecido restos de madera carbonizada. La ausencia de carbón en la zona septentrional (A) puede deberse al uso de otro tipo cubierta, quizá de piedra en forma de falsa cúpula, aunque tampoco hay restos en este sentido. No hay que descartar que la falta de evidencias relacionadas con la cubrición, ya fuese de piedra o de madera, se deba al desmantelamiento posterior de sus restos.

\subsection{Fase de utilización}

La tumba fue utilizada durante un dilatado periodo de tiempo. Si tenemos en cuenta que el número mínimo de individuos (NMI) asciende a 91, debió extenderse a varias generaciones. La estimación, realizada a partir la porción petrosa del hueso temporal, determina una distribución de 61 individuos en la zona principal de la cámara, 16 en el sector meridional (B) y 14 en el corredor. 


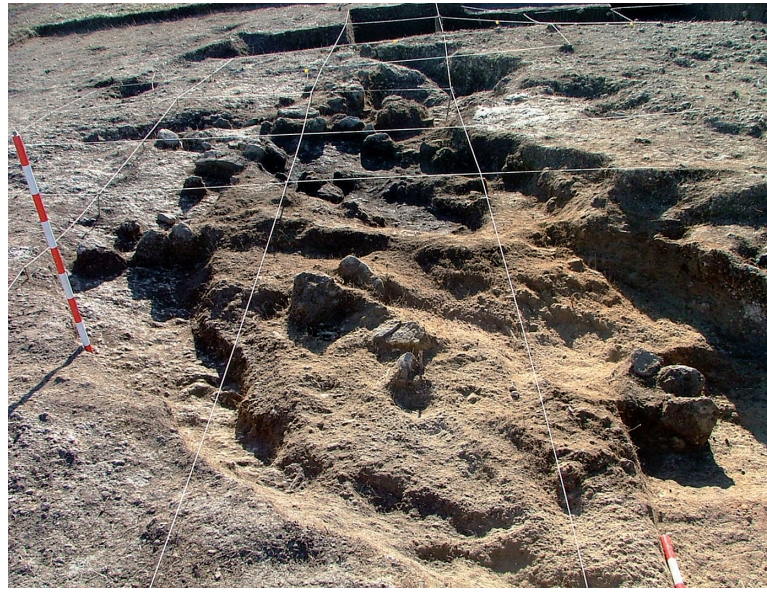

Fig. 4. El Hundido (Monasterio de Rodilla, Burgos), proceso de excavación de la tumba colectiva. Por efecto de las altas temperaturas la piedra caliza de la estructura se transformó en óxido de cal, y vitrificó la arena que cubría los restos óseos.

Esta valoración, sin embargo, es relativa ya que, como se verá, los restos óseos fueron recuperados removidos y fragmentados, y la reordenación intencionada de determinadas partes del esqueleto durante el uso de la tumba, particularmente de cráneos, finalmente alteró la posición inicial de los restos. En la zona septentrional (A) se concentra el $70 \%$ de los restos óseos, en la zona meridional (B) el 19\% y en el corredor el 11\%. Este último porcentaje es muy elevado, ya que su superficie útil es de poco más de $2 \mathrm{~m}^{2}$.

Antes de abordar el complejo ritual documentado, aludiremos brevemente a las alteraciones físicas que han sufrido los restos óseos a lo largo del tiempo. Ya durante la fase de utilización inicial de la tumba, la intensa remoción de los restos derivada de las prácticas rituales ocasionó una importante fragmentación (Fig. 3A). Después, durante la fase de clausura, las altas temperaturas produjeron deformaciones y nuevas fragmentaciones en los huesos. Además, el calor transformó en óxido de cal la roca caliza de los muros longitudinales y vitrificó la arena con la que finalmente fue rellenada la cámara principal, cimentando todo el conjunto. Sin embargo, estos factores no han impedido determinar con bastante precisión el tratamiento que se dio a los inhumados en cuanto a la distribución de los restos óseos, a su sexo y edad de muerte.

Destacamos agrupamientos de piedras calizas y cuarcíticas tendentes a alinearse en las zonas septentrional de la cámara (A) (U.E. 375) y meridional (B) (U.E. 510), que podría indicar la compartimentación del espacio (Fig. 3B), aunque en esta última tendrían más bien una función de sustentación de los restos.

Lo cierto es que todos los inhumados se removieron en un momento dado y, en muchos casos, parte de sus restos se trasladaron y ordenaron de manera intencionada. El estudio antropológico ha revelado que cuando esto sucedió en algunos individuos no se había completado la pérdida de tejidos blandos y que, en el momento de la clausura, había tanto restos óseos antiguos o 'secos' como recientes o 'frescos'.

\subsubsection{Primera fase ritual}

Todo indica que los cuerpos fueron inicialmente inhumados en la zona septentrional (A) de la cámara, la más profunda y también la mejor protegida por los dos muros longitudinales. En este momento podemos hablar de inhumación primaria, aunque cuando a medida que se iban introduciendo nuevos cuerpos se removían los anteriores para habilitar espacio. Como resultado, los huesos aparecieron amontonados y tan entremezclados que las conexiones anatómicas son muy excepcionales (Fig. 5).

Posteriormente algunos de los restos fueron seleccionados y reordenados en la propia zona septentrional (A), o trasladados a la meridional (B). Esta constante remoción explica la fracturación, primero como resultado de la introducción de nuevos cuerpos y finalmente por los procesos de traslado y reorganización. Los restos trasladados a la zona meridional (B) fueron seleccionados y agrupados, ya que mayoritariamente el conjunto está integrado por huesos largos agrupados en haces y por 'nidos de cráneos'. Se observa cierta distribución lineal y una cuidada colocación, a lo que contribuyen los agrupamientos de piedras y la morfología de la grieta abierta en el sustrato calizo. Los cráneos fueron depositados y orientados de modo diverso sin que se aprecie una predilección en la norma, pero nunca volteados. Las conexiones anatómicas documentadas se limitan a vértebras cervicales asociadas a algunos cráneos, lo que implica que en el momento de su traslado aún existían tejidos blandos. 


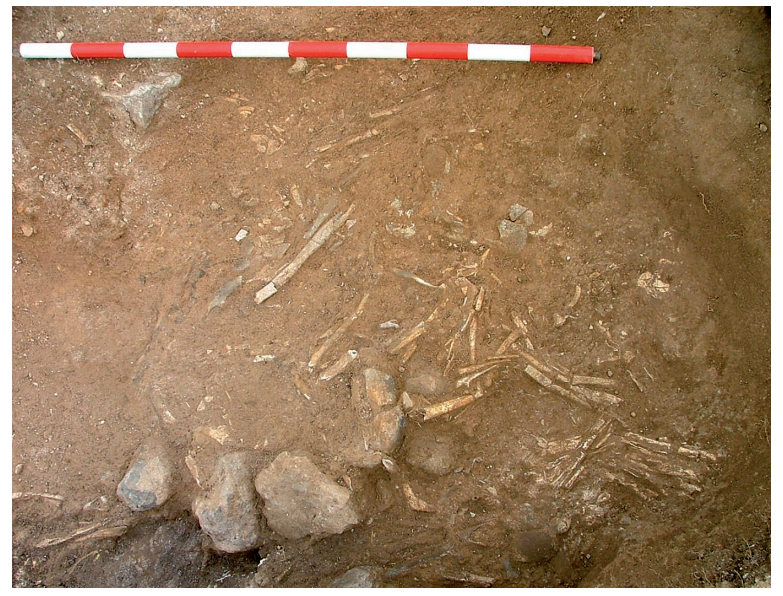

Fig. 5. El Hundido (Monasterio de Rodilla, Burgos), tumba colectiva. Los restos óseos documentados en la zona septentrional de la cámara aparecieron muy fragmentados y en posición secundaria.

En la zona meridional (B) se han individualizado 28 cráneos, aunque la contabilización de porciones petrosas del hueso temporal determina un NMI de 16 en este sector, ya que los cráneos no están completos, tratándose en realidad de calotas. Los fragmentos que faltan, incluidas muchas de las porciones petrosas, debieron quedarse en el interior de la zona septentrional de la cámara (A). Esto explicaría, por ejemplo, por qué junto al cráneo $n^{\circ} 375-25$ han sido recogidas porciones petrosas de 10 individuos. Todo indica que pueden tratarse de actos de rotura intencionada similares a los realizados sobre los denominados 'cráneos copa', aunque ninguno ha aparecido en esta posición. Por otra parte, 13 cráneos fueron depositados junto con fragmentos de mandíbula que no conservan restos de maxilar.

En la zona septentrional de la cámara (A) han sido individualizados 49 cráneos, aunque las porciones petrosas recuperadas determinan un NMI de 61. También aquí se aprecian ciertas agrupaciones, si bien la elevada fragmentación ha dificultado particularmente su identificación. Se puede hablar de una tendencia general a su agrupación en el tercio meridional, donde se localiza en torno a la mitad. Destaca un 'nido' formado por siete cráneos justo en la entrada del corredor. Esta posición indica que debieron ser agrupados poco antes de la clausura de la tumba ya que, de lo contrario, habrían sido removidos con la intro- ducción de nuevos cuerpos. Posiblemente la agrupación de cráneos en el momento de la clausura también ocurrió en el corredor, donde el NMI es 11 , muy elevado en proporción al volumen total de huesos recuperados $(14,6 \mathrm{~kg})$.

Como no hay ningún individuo en posición primaria, cabe pensar que cuando la tumba fue clausurada se esperó a que el cuerpo del último inhumado estuviera descompuesto para ser posteriormente desmembrado. Todo apunta que pudo tratarse del $n^{\circ} 375-40$, una mujer de edad de muerte superior a 40 años que presenta algunos restos óseos en conexión anatómica. Fue documentada en una zona próxima al corredor y centrada con respecto a la cámara, y las alteraciones térmicas observadas sugieren que los huesos estaban frescos en el momento de la clausura.

Parece evidente que únicamente ciertos individuos de los inicialmente inhumados en la zona septentrional de la cámara (A) contaron con el 'privilegio' de que algunos de sus restos fueran trasladados a la zona meridional (B). Lo sencillo sería recurrir a los clásicos argumentos de rango social para explicar esta parte del ritual, pero a falta de otras evidencias sería especulativo. No sabemos si eran o no individuos destacados en el grupo pero, si lo eran, sus cuerpos tuvieron que seguir siendo identificables tras ser depositados en la zona septentrional de la cámara para evitar 'traslados erróneos' a la zona meridional tras su descomposición.

Por otro lado, exceptuando algunas piezas líticas y pequeños fragmentos cerámicos, destaca la ausencia de ajuares en la zona septentrional. Ello puede estar relacionado con la permanencia temporal de los restos, o al menos de una parte de ellos, en este espacio, lo que quizá puede explicarse por entender el funeral como un rito de paso (Metcalf y Huntington 1991: 84).

El material recuperado en el corredor y en la zona septentrional está integrado por 31 piezas de industria en sílex, 144 fragmentos cerámicos, 2 cuentas de collar líticas y 1 fragmento de punzón de hueso. La distribución topográfica evidencia una notable concentración de materiales en el corredor, de donde procede más de la mitad de la industria lítica y de la cerámica así como las dos cuentas de collar. Sin embargo, en la zona meridional han sido localizados varios recipientes cerámicos en el extremo sur, en coincidencia con el máximo estrechamiento de la grieta, fuera del ámbito destinado a los restos humanos. No 
se aprecian alteraciones térmicas, lo que puede deberse a que fueron depositados tras la clausura de la tumba o a que su posición marginal con respecto al foco de calor les liberara de sus efectos.

Todo el conjunto óseo, al margen de su localización, muestra en mayor o menor grado pequeñas tinciones de color anaranjado de origen mineral que sugieren el uso de pigmentos durante el ritual funerario. Este mismo material está presente en el sedimento de cubrición de los restos en forma de pequeñas intrusiones, aunque no parece formar parte de su composición mineral natural.

\subsubsection{Distribución en función del sexo y edad de muerte}

La tumba acogió a personas de ambos sexos y de todos los rangos de edad. La localización de las 77 calotas documentadas no permite hablar de agrupamientos $\mathrm{u}$ ordenaciones en base a la edad (Fig. 6A). Sin embargo, la distribución del conjunto de restos óseos perteneciente a individuos de edad de muerte inferior a 14 años, muestra su ausencia casi total en la zona meridional de la cámara (B) y en los flancos este y oeste de la septentrional (A). En general, los restos de individuos infantiles de hasta 6 años de edad de muerte aumentan a mayor proximidad al centro de la cámara y del corredor, aunque las únicas tres calotas individualizadas presentan una localización perimetral. Por otro lado, los restos de individuos infantiles entre 7 y 14 años de edad de muerte se distribuyen por sectores orientales, mientras que en el corredor existen restos de ambos grupos.

En la zona meridional (B) la presencia de restos infantiles es testimonial. Se limita a una calota y a los restos de un fémur identificados entre calotas de los individuos adultos, por lo que pudo

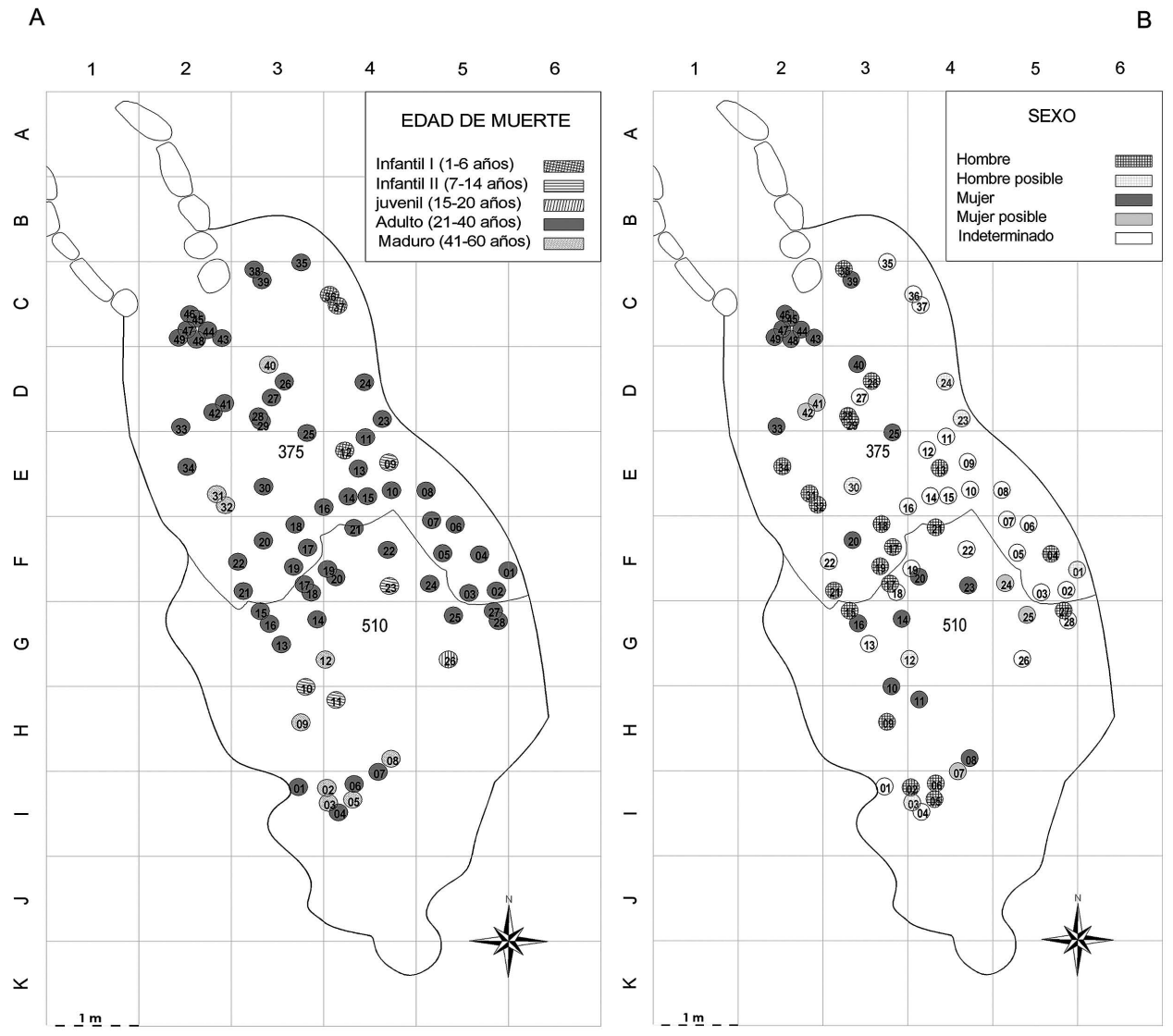

Fig. 6. El Hundido (Monasterio de Rodilla, Burgos), tumba colectiva. Distribución de las 77 calotas identificadas: A. en función de la edad de muerte; B. en función del sexo. 
ser extraído de la zona septentrional de manera no intencionada junto con otros huesos largos.

En los 73 individuos de edad de muerte superior a 15 años, la presencia de mujeres $(47,16 \%)$ es ligeramente inferior a la de los hombres $(52,83 \%)$ (Fig. 6B). La ordenación por sexos se aprecia en dos casos, el primero particularmente evidente. Se trata de los siete cráneos (n ${ }^{0}$ 375-43 a 375-49) localizados justo en la entrada del corredor a los que ya se ha hecho referencia, pertenecientes a mujeres entre 21 y 40 años. Además, su localización coincide con el ámbito donde los restos infantiles abundan más. En el segundo caso se agrupan cuatro cráneos pertenecientes a individuos masculinos $\left(\mathrm{n}^{\mathrm{o}} 510-02,510-03,510-05,510-06\right)$, aunque significativo, también puede deberse a un hecho fortuito.

\subsection{Fase de clausura: condenación de la tumba y segunda fase ritual}

La clausura de la tumba colectiva debió producirse cuando en la zona septentrional de la cámara (A) y el propio corredor no quedaba espacio para nuevos enterramientos, aunque la superficie libre de la zona meridional (B) todavía era considerable. Entonces, se procedió a la colmatación total de la zona septentrional mediante cuatro capas sedimentarias sucesivas: tres de arena y una de arcilla. Si la cubierta hubiese sido vegetal, esta labor se habría visto facilitada al poder retirarla con comodidad.

Cubierto todo el conjunto, se procedió a su clausura definitiva mediante un fuego controlado, cuya intensidad y duración bastó para transformar el carbonato cálcico de la roca caliza de los muros longitudinales en óxido de cal y vitrificar la arena que cubría los restos óseos. Los signos de la rubefacción se evidencian en la intensa coloración anaranjada de los sedimentos de cubrición de la zona septentrional de la cámara (A). En la zona meridional (B), donde en general las temperaturas alcanzadas fueron inferiores, se produjo una combustión reductora que ennegreció el sedimento de manera más o menos intensa (Fig. 7). Como se verá más adelante, la coloración de los restos óseos ha permitido estimar la temperatura alcanzada en cada zona de la cámara (hasta $1.000^{\circ} \mathrm{C}$ ). El aporte de agua necesario para transformar el óxido de calcio en hidróxido de calcio y provocar su cimentación pudo ser voluntario o fortuito, por acción de la lluvia, pero contribuyó decisivamente al sellado de la estructura una vez arruinada.

La localización de determinados materiales arqueológicos indica que tras la condenación de la tumba se realizó un nuevo ritual que incluyó el depósito de ofrendas. Si exceptuamos los recipientes cerámicos documentados en el extremo sur de la zona meridional (B), sobre la superficie de la tumba y su entorno inmediato han sido recogidas 32 piezas líticas, 128 fragmentos cerámicos, 2 cuentas de collar, 2 percutores y 1 fragmento de hacha pulimentada. Hay que tener en cuenta que el laboreo agrícola, realizado posiblemente desde época romana y hasta hace tan solo unas décadas, ha podido contribuir a su desplazamiento, aunque el material aparece principalmente sobre la superficie tumular y su entorno inmediato.

Caso diferente es el de los recipientes cerámicos concentrados al sur de la cámara meridional (B) (Fig. 8). Se trata de 11 cuencos y 1 cazuela que aparecieron en el interior de pequeñas oquedades existentes en la grieta natural: la cazuela y dos de los cuencos en solitario, uno de ellos junto a un percutor, y el resto en dos grupos de tres y seis recipientes distanciados apenas $20 \mathrm{~cm}$. Podrían estar relacionados con la práctica de ofrecer alimentos a los muertos, aunque algunos aparecieron boca abajo. De ser así las ofrendas debieron ser principalmente vegetales o líquidos, ya que la presencia de restos faunísticos durante la excavación ha sido

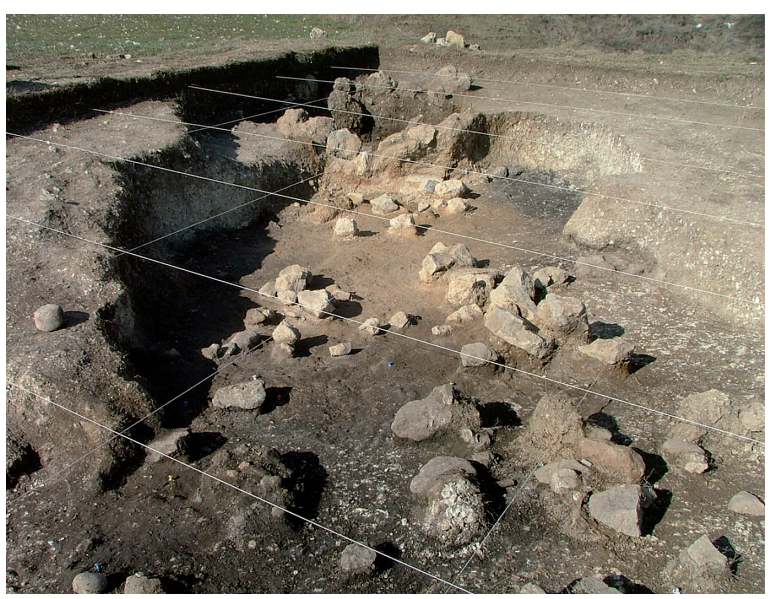

Fig. 7. El Hundido (Monasterio de Rodilla, Burgos).Vista desde el sur de la tumba colectiva. La coloración está relacionada con el tipo de combustión: oxidante en la zona septentrional y reductora en la meridional. 


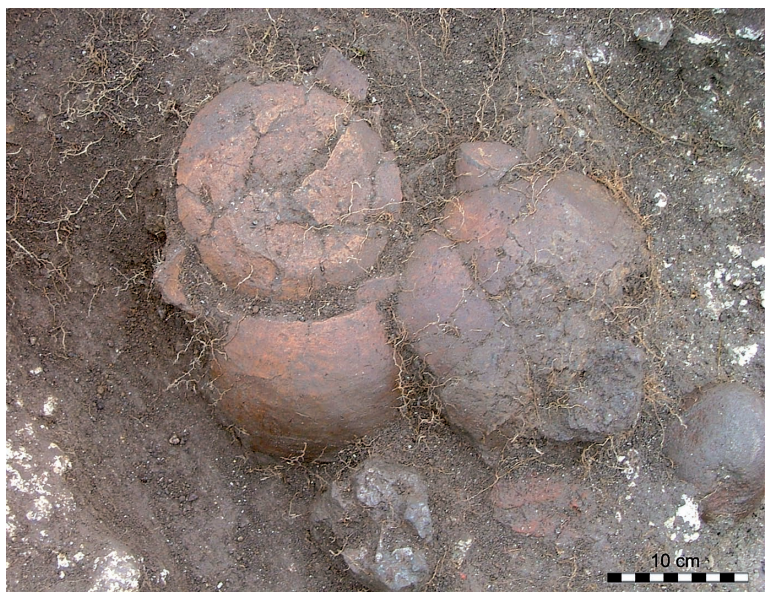

Fig. 8. El Hundido (Monasterio de Rodilla, Burgos), tumba colectiva. Detalle de algunos de los recipientes cerámicos documentados en la zona meridional de la cámara, relacionados con depósitos votivos.

testimonial. Se redujo a un astrágalo de ovicáprido y a un calcáneo de zorro en la zona meridional de la cámara (B), y a algunos molares de ovicáprido situados en el corredor pero que también pudieron ser introducidos en la fase campaniforme.

\section{MATERIALES ARQUEOLÓGICOS}

Comprenden piezas de sílex, cerámicas, rocas duras y elementos óseos. Se presentarán primero sus características tecnológicas y tipología y después su distribución y aspectos funcionales.

\subsection{Industria lítica}

En total 63 piezas están asociadas a la tumba colectiva, aunque únicamente 31 tienen una relación directa con el nivel funerario. El resto fueron depositadas con posterioridad a la clausura de la tumba y han sido recogidas sobre la superficie tumular o en el ámbito inmediato. Las piezas están realizadas sobre sílex, excepto una lámina tallada sobre cuarcita. El sílex es de buena calidad, siempre de granulometría fina y por lo general de aspecto opaco, con preferencia de color blanco y gris. No se evidencian signos de desilificación, aunque sí alteraciones térmicas producidas por la acción del fuego en los materiales procedentes del interior de la cámara. En este sentido, los cambios de coloración (del gris claro al negro) afectan a la totalidad de la pieza, por lo general en forma de manchas con distintos matices cromáticos. También son frecuentes las pátinas blanquecinas, las superficies craqueladas y la pérdida del brillo natural de la materia prima. La elevada temperatura también ha sido responsable de algunas fragmentaciones. Estas alteraciones térmicas, que hacen su aparición cuando el sílex experimenta temperaturas superiores a $350^{\circ}$ C (Terradas y Gibaja 2001: 33-36), faltan en el resto del material lítico, depositado tras la clausura de la tumba o lo suficientemente alejado del foco de calor como para no verse afectado por el.

Es clara la preferencia por los soportes laminares $(70,97 \%)$ sobre las lascas $(20,97 \%)$ y las lascas laminares $(8,06 \%)$, y la ausencia de núcleos. Destaca la buena factura de los soportes laminares y su tendencia a filos paralelos y secciones trapezoidales. En cambio, en las piezas retocadas las armaduras completas son testimoniales: un perforador (Fig. 9:1) y una punta foliácea (Fig. 9:2).

Atendiendo a aspectos tipométricos, como resultado del elevado índice de fracturación solo 6 piezas superan los $30 \mathrm{~mm}$ de longitud. El rango de la mayoría oscila entre 11 y $26 \mathrm{~mm}$. Por su anchura, han sido clasificadas como laminillas las piezas donde ésta es igual o inferior a $12 \mathrm{~mm}$, y láminas aquellas que superan la medida. Como resultado, de los 44 soportes laminares en sílex el $57 \%$ son laminillas y el $43 \%$ láminas. Solo seis de estas últimas superan los $15 \mathrm{~mm}$ de anchura y ninguna sobrepasa los $20 \mathrm{~mm}$ (Fig. 10A).

Las lascas y lascas laminares simples suman 17 (26,98\% de la colección). Las demás piezas pueden clasificarse en una amplia tipología (Fig. 10B). Las mejor representadas son las láminas y laminillas simples $(36,51 \%$ del total), lo que supone que el $63 \%$ de las piezas no están retocadas. Las láminas y laminillas retocadas ascienden a $11,11 \%$ con 5 ejemplares de dorso y 2 de doble dorso (Fig. 9: 4). El retoque predominante es el modo simple, bien marginal o profundo, y casi siempre directo, con un ejemplo alternante.

En las muescas $(7,94 \%)$ y denticulados $(4,76 \%)$ predominan las laminillas sobre las láminas, y el modo simple de retoque, aunque una muesca y un denticulado (Fig. 9: 5) muestran retoque abrupto profundo. 

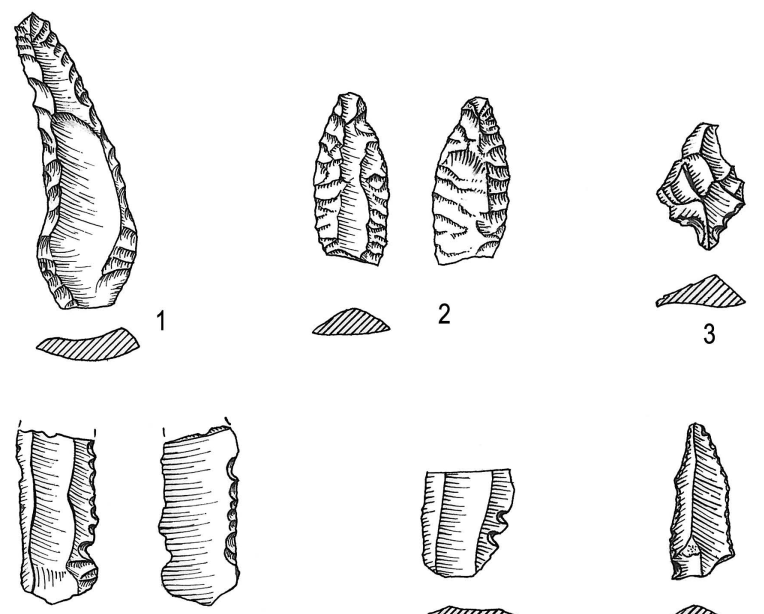

4

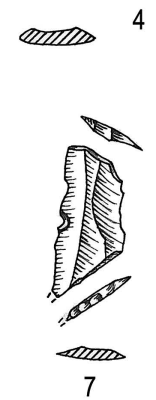

7
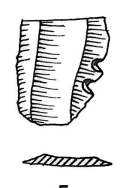

5
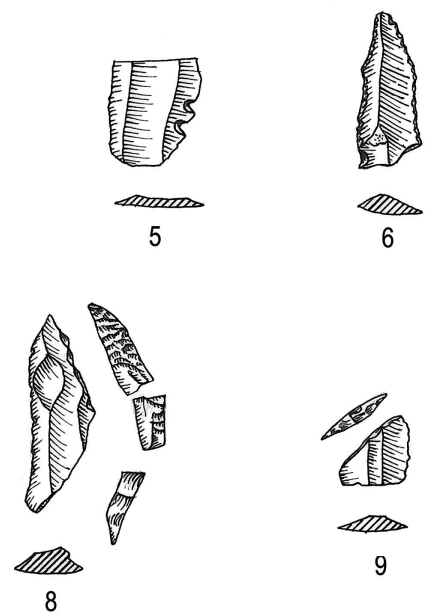

9
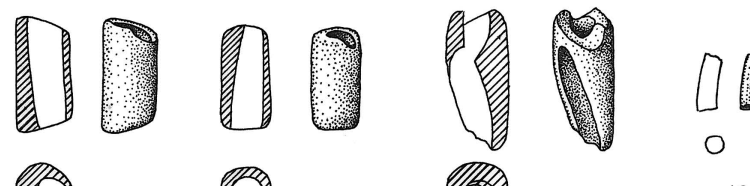

12
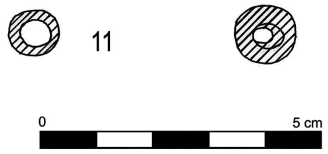

Fig. 9. El Hundido (Monasterio de Rodilla, Burgos), tumba colectiva: 1-9. industria lítica en sílex; 10-12. cuentas de collar líticas; 13. cuenta de collar sobre Antalis. Dibujo Belén Alonso.

Se han recuperado 3 puntas: una sobre laminilla de doble dorso con retoque simple y profundo (Fig. 9: 6) de $26 \mathrm{~mm}$ de longitud y $11 \mathrm{~mm}$ de anchura y dos con retoque plano de tipo foliáceo (Fig. 9: 2) y pedunculado (Fig. 9: 3). La foliácea de retoque bifacial está muy afectada por la acción térmica. Mide $30 \mathrm{~mm}$ de longitud conservada y 12 $\mathrm{mm}$ de anchura máxima. La punta pedunculada es de torpe factura. Está retocada por una de sus caras y mide $11 \mathrm{~mm}$ de longitud y $14 \mathrm{~mm}$ de anchura.
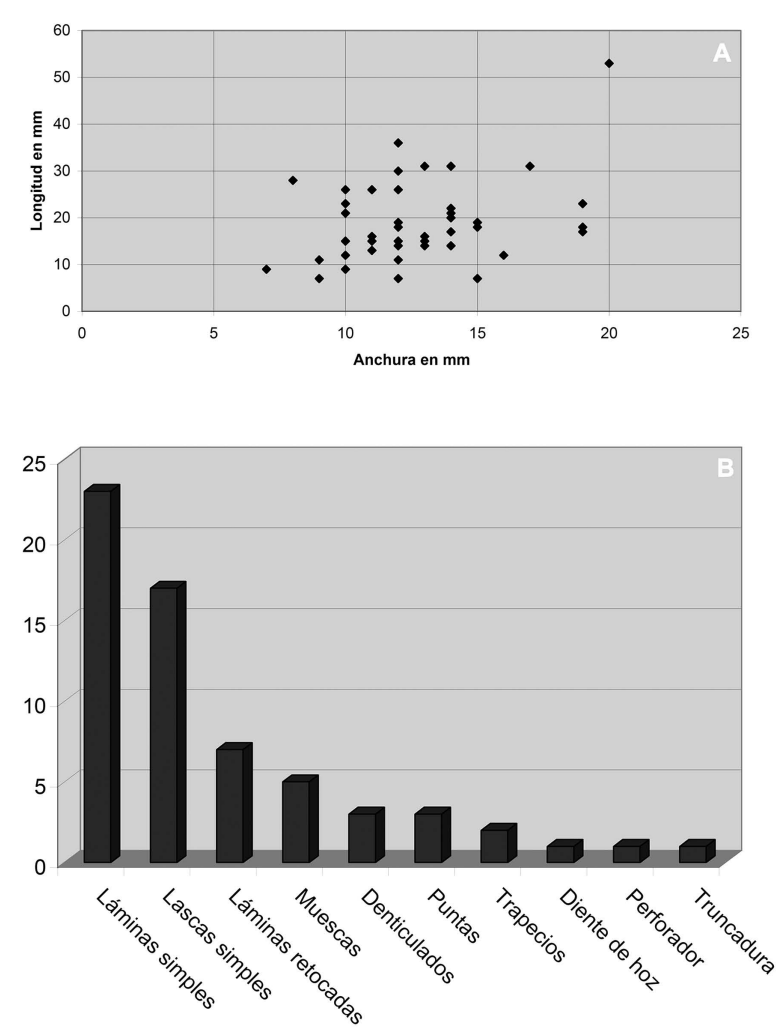

Fig. 10. El Hundido (Monasterio de Rodilla, Burgos): A. Gráfico de dispersión de los soportes laminares procedentes de la tumba colectiva en relación a su anchura; B. Tipología de la industria lítica asociada.

Las dos bitruncaduras recuperadas son trapecios $(3,17 \%)$ con retoque abrupto directo de forma recta. Uno tiene la base menor retocada (Fig. 9: 8) y mide $36 \mathrm{~mm}$ de longitud, $12 \mathrm{~mm}$ de anchura y $6 \mathrm{~mm}$ de grosor. El otro trapecio es algo más corto y delgado. Mide $26 \mathrm{~mm}$ de longitud, $12 \mathrm{~mm}$ de anchura y $3 \mathrm{~mm}$ de grosor (Fig. 9: 7).

Además hay un perforador, una truncadura oblicua y un diente de hoz (1,59\% en cada caso). El soporte laminar del perforador (Fig. 9: 1) es el más largo de los documentados: mide $52 \mathrm{~mm}$ de longitud y $20 \mathrm{~mm}$ de anchura y apareció fracturado por la acción térmica, tiene forma puntiforme ligeramente desviada y ambos dorsos retocados, el izquierdo plano y el derecho simple de tendencia a plano. El soporte de la truncadura (Fig. 9: 9) es una laminilla de $12 \mathrm{~mm}$ de longitud y $10 \mathrm{~mm}$ de anchura, contando con retoque abrupto directo. El diente de hoz está realizado sobre lasca de talón cortical. 
En relación a la distribución topográfica de las piezas depositadas con carácter previo a la clausura de la tumba (Fig. 11B) únicamente se observa una concentración en el corredor, donde han sido recuperadas más de la mitad de las piezas $(51,61 \%)$. El resto se distribuye de manera dispersa en el ámbito septentrional (A) $(38,71 \%)$ y meridional (B) $(9,68 \%)$ de la cámara. En el primero únicamente seis piezas han estado en contacto con los restos óseos, procediendo las demás de los diferentes sedimentos de relleno. De aquí proceden los dos trapecios, la punta foliácea y el perforador de retoque plano.

Las 32 piezas depositadas tras la clausura de la tumba carecen de distribuciones y agrupamientos concretos (Fig. 11A). Hay que tener en cuenta que la mayoría han sido recuperados en la cobertera vegetal, y que el laboreo de este ámbito ha debido contribuir a modificar su posición. No obstante, se observa una clara tendencia a ocupar la superficie tumular y su entorno inmediato. Entre las piezas están la punta pedunculada, la truncadura y el diente de hoz.

Por último, parece que el conjunto lítico fue fabricado con carácter meramente ritual, dada la ausencia de huellas de uso al menos a partir de la observación macroscópica. Únicamente hay una excepción: el elemento de hoz manifiesta el característico brillo de cereal.

\subsection{Cerámica}

El conjunto cerámico asciende 956 fragmentos, pertenecientes a un número máximo estimado

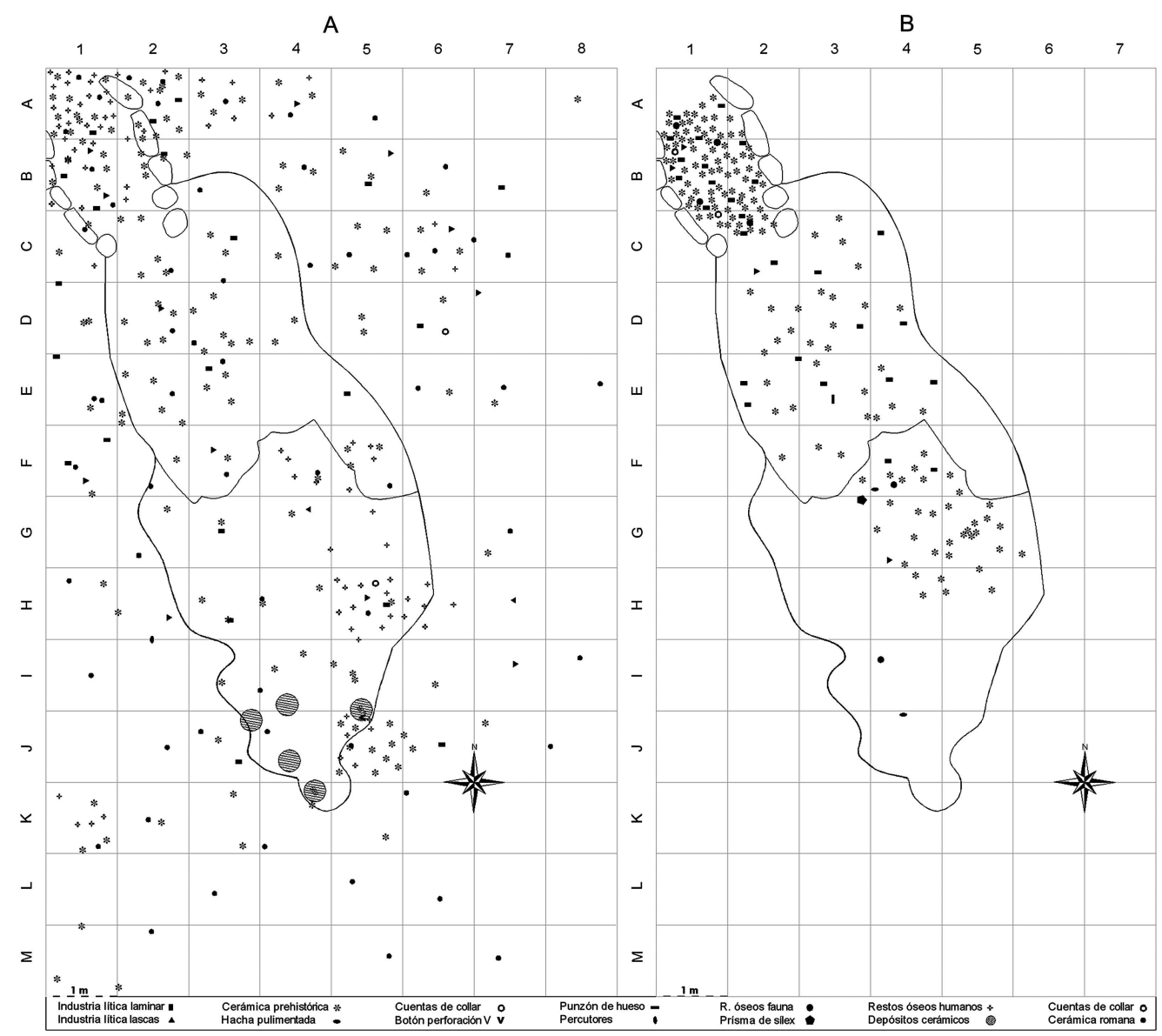

Fig. 11. El Hundido (Monasterio de Rodilla, Burgos). Distribución del material arqueológico de la tumba colectiva: A. depositado tras la clausura; B. depositado en el interior de la cámara funeraria. 
de 31 recipientes. Entre ellos hay cinco perfiles completos y siete perfiles superiores recuperados en la zona meridional de la cámara (B) que integran los depósitos votivos.

La tecnología es bastante homogénea. Se han empleado arcillas sedimentarias con cuarzo y mica de granulometría fina y en ningún caso abundante, aunque la presencia de otro tipo de granulometrías y desgrasantes permite establecer otros dos tipos de pastas con igual representación: una con abundante contenido en cuarzo y otra con carbonatos de calibres gruesos que definen un característico aspecto 'aturronado'.

Las cocciones son oxidantes $(45,16 \%)$, mixtas reductoras con postcocción oxidante $(35,48 \%)$ o reductoras $(19,35 \%)$. En las primeras, son frecuentes las manchas negruzcas o grisáceas. El tratamiento superficial mayoritario es el alisado más o menos depurado, con algún espatulado o pseudobruñido siempre inferior al 10\%.

Los recipientes son de tamaño mediano (entre 12 y $21 \mathrm{~cm}$ de diámetro), con paredes de 4-8 mm de grosor. El elenco formal está representado por perfiles simples basados en la esfera, de tendencia globular o hemisférica, los primeros con bordes de tendencia cerrada y abierta los segundos. Los labios son redondeados $(46,88 \%)$, planos $(21,88 \%)$ y afinados $(31,25 \%)$, estos últimos con una característica inflexión justo en su inicio. Fuera de esta norma existe un pequeño fragmento de borde perteneciente a un perfil ligeramente sinuoso de cuello insinuado, recuperado en la cobertera vegetal. Los fondos son de tres tipos: planos aunque de arista redondeada, cóncavos y uno ligeramente umbilicado (Fig. 12: 9).

El número de piezas decoradas $(21 \%)$ se puede considerar alto en relación a la mayoría de los conjuntos calcolíticos. Sin embargo, el elenco de técnicas y motivos es muy escueto: decoración aplicada, un caso de impresión -labio con una sucesión de segmentos- y otro de incisión -línea que circunda el labio de un cuenco-. Las aplicaciones, mediante finas orejeras que en ocasiones se alargan hasta formar estilizados cordoncillos, se localizan siempre bajo los labios.

El repertorio formal comprende una cazuela y al menos 23 cuencos que pueden englobarse en dos tipologías: perfiles globulares cerrados de fondo cóncavo o plano y perfiles hemisféricos abiertos de fondo cóncavo, plano o umbilicado. Entre los perfiles globulares cerrados destaca una cazuela de labio y fondo planos (Fig. 12: 1) por su interesante decoración a base de finos cordoncillos biselados localizados bajo el labio y dispuestos dos a dos, en un caso en forma de cruz y en vertical en el otro. Entre los cuencos (12-16 cm de diámetro), cabe mencionar uno de labio redondeado y fondo cóncavo decorado con dos finas orejeras contrapuestas localizadas bajo el labio y aparentemente una tercera, en este caso impar, en la zona inferior de la panza (Fig. 12: 3). A este mismo tipo de perfil pertenecen otras piezas decoradas con orejeras (Fig. 12: 2 y 4), en algunos casos en disposición perpendicular y con afinamiento de las paredes a la altura del labio (Fig. 12: 8 y y 10).

Entre los perfiles hemisféricos abiertos (diámetros de 14-22 cm), destaca uno completo de fondo plano y labio afinado (Fig. 12: 11), muy similar

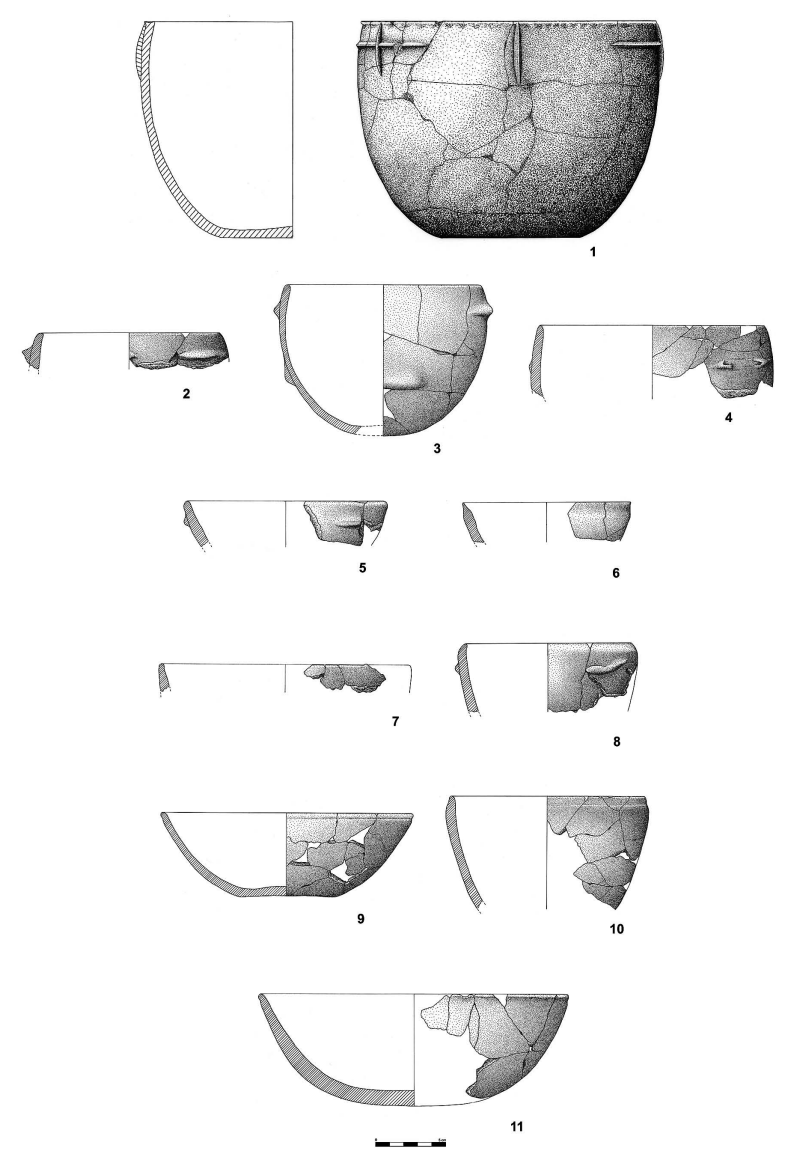

Fig. 12. El Hundido (Monasterio de Rodilla, Burgos), tumba colectiva. Materiales cerámicos. Dibujo Margarita Alonso (1) y Belén Alonso (2-11). 
al la pieza de fondo ligeramente umbilicado (Fig. 12: 9). En ocasiones el afinamiento de los labios determina una marcada inflexión en su unión con la pared de cuenco (Fig. 12: 2). Por último, también hay piezas de borde redondeado (Fig. 12: 5 y 7).

En la distribución destaca el elevado número de fragmentos localizados en el corredor (Fig. 11B). Aparecen en posición derivada, porque primeramente fueron extraídos para construir la cista campaniforme y nuevamente utilizados como material de relleno. Parte de su fragmentación se puede atribuir a estas acciones, pero todo parece indicar que fue previa a su introducción ya que sólo se cuentan cuatro bordes entre los 80 fragmentos. Representan el 55,5\% de las piezas asociadas directamente a la tumba antes de ser clausurada.

En la zona septentrional (A) de la cámara se observa una dispersión de pequeños 64 pequeños fragmentos, que también se extiende a la zona más próxima de la meridional (B). En la zona septentrional solo nueve estuvieron en contacto directo con los restos óseos, mientras que los demás formaban parte de las diferentes capas de relleno. También aquí podemos afirmar que el material ya estaba fragmentado cuando fue depositado. Circunstancia muy distinta sucede en el resto de la zona meridional de la cámara, donde la ausencia de fragmentos es total y sin embargo han sido documentados hasta 12 recipientes completos o prácticamente completos. Estos recipientes, posiblemente portadores de ofrendas, se localizaron en el extremo de la grieta natural y es probable que fueran depositados en el momento de la clausura de la tumba o bien a posteriori.

Por encima del nivel de clausura han sido recuperados 128 fragmentos y, como sucede con la industria lítica extractiva, sin distribuciones ni agrupamientos concretos (Fig. 11A). En la superficie, junto con algunos materiales romanos, se observa una dispersión general, lo mismo que en la cobertera vegetal, aunque en este caso con agrupamientos en los cuadros de excavación A1 (ámbito del corredor) y J5, en el entorno donde fue recuperado el cuenco umbilicado.

\subsection{Otros materiales arqueológicos}

En este grupo destaca el hallazgo en superficie de un fragmento distal de hacha pulimentada pequeña realizada en ofita, materia prima fácil de encontrar en territorios relativamente cercanos al yacimiento. Mide $32 \mathrm{~mm}$ de longitud y $14 \mathrm{~mm}$ de anchura.

De la zona meridional de la cámara proceden 2 percutores realizados sobre guijarros naturales de cuarcita y 1 pieza de sílex fragmentada por efecto de la alta temperatura, que en esta zona debió situarse entre 550 y $600^{\circ} \mathrm{C}$. De hecho, presenta un tipo de roturas de morfología poliédrica y angular, que se producen a partir de una exposición térmica superior a $500^{\circ} \mathrm{C}$ (Terradas y Gibaja 2001: 36). En origen pudo tener forma esférica y unos $6 \mathrm{~cm}$ de diámetro, presentando talla poliédrica sin restos de córtex.

En el interior del corredor ha sido recuperado un fragmento de cuenta de collar realizada sobre Antalis inaequicostalum (Fig. 9: 13) con signos de carbonización. Además han sido recogidas tres cuentas de collar cilíndricas de piedra de 25, 21 y $13 \mathrm{~mm}$ de longitud. Una procede del corredor (Fig. 9: 10) y las otras dos de la cobertera vegetal: una fuera de la superficie tumular (Fig. 9: 12) y otra en su zona suroriental (Fig. 9: 11).

En el interior de la cámara, en el ámbito septentrional y en contacto con los restos óseos, ha sido recuperado el extremo distal de un punzón óseo de sección circular. Procede de una zona que estuvo sometida a una temperatura superior a $650^{\circ} \mathrm{C}$, de ahí que presente el característico color blanco de calcinación. Finalmente, no ha sido recuperado ningún objeto metálico, pero sí un peroné y una falange humanos cuya superficie de color verdoso, aparentemente producto de la transferencia por contacto de objetos de cobre.

\section{RESTOS ÓSEOS HUMANOS}

\subsection{Conservación y grado de representación}

El estado de conservación de los restos óseos viene determinado por el lugar que ocuparon dentro de la cámara, observándose diferencias considerables entre los situados en la zona septentrional (A) y la meridional (B). En ambos casos fueron sometidos a diferentes variables antes de la clausura de la tumba, durante este proceso y

Trab. Prehist., 72 N $^{\circ}{ }^{\circ}$ 1, enero-junio 2015, pp. 84-104, ISSN: 0082-5638

doi: $10.3989 /$ tp. 2015.12145 
posteriormente. Como se ha visto en el apartado dedicado a los aspectos rituales, antes de la clausura los situados en la zona septentrional (A) fueron sistemáticamente removidos, por lo que ya en ese momento debieron sufrir numerosas fracturas. Sin embargo, los situados en la zona meridional (B) fueron seleccionados y ordenados, con menor grado de fracturación.

La temperatura alcanzada durante la fase de clausura combinada con la diferente humedad de los huesos, originaron respuestas físicas distintas. Como el calor alteró su color en función de la temperatura de exposición, las diferencias cromáticas permiten determinar con bastante precisión los grados alcanzados en cada zona de la cámara. Siguiendo la clasificación cromática de los huesos propuesta por Etxeberría (1994), se han establecido seis fases de combustión.

Los restos localizados en el corredor, prácticamente la totalidad de los de la zona septentrional de la cámara y de un pequeño sector de la meridional (Fig. 13A), estuvieron sometidos a temperaturas superiores a $650^{\circ} \mathrm{C}$ (Fase VI) y, considerando que se produjo la transformación del carbonato cálcico en óxido de cal, la temperatura llegó en muchas zonas a unos $1.000^{\circ} \mathrm{C}$. La mayoría de los huesos han tomado aspecto mineralizado y cristalino, adquiriendo considerable dureza y elevado peso específico. Muestran el característico color blanquecino, excepto los situados en contacto con el suelo en los flancos oriental y occidental, los cuales son de color gris azulado y están más próximos a la carbonización que a la incineración. En cambio, los inmediatamente superiores también son de color blanco. La temperatura alcanzada fue inferior en la zona meridional de la cámara (B), descendiendo progresivamente con la distancia al foco principal de calor. En una amplia franja la temperatura debió situarse entre los $550-600^{\circ} \mathrm{C}$ (Fase V), afectando marginalmente a los restos de la zona septentrional (A) y a buena parte de los situados en la meridional (B).

A partir de esta amplia franja se suceden de manera radial y en dirección sur-sureste otras dos. En la primera, de unos $20 \mathrm{~cm}$ de anchura, la coloración negruzca de los restos indica que la temperatura se situó entre los $300-350^{\circ} \mathrm{C}$ (Fase IV). En la siguiente, de mayor anchura, el color marrón es propio de temperaturas situadas entre los 250-300 $\mathrm{C}$ (Fase III). En su extremo meridional se observa un repunte de temperatura entre $550-650^{\circ} \mathrm{C}$ (Fase V), en concreto en las cuadrículas $\mathrm{H} 4$ e I4, ámbito que coincide con la existencia de dos bloques de conglomerado. Sus características geológicas pudieron contribuir puntualmente a una mayor conservación de la temperatura, aunque en esta zona también pudo haber un fuego secundario. Por último, se suceden dos nuevas franjas de las Fases III y IV, a la par que se observa un pequeño ámbito donde la temperatura alcanzó entre $200-250^{\circ} \mathrm{C}$ (Fase II). Los únicos restos óseos sin alteración térmica (Fase I) forman un pequeño grupo localizado fuera de la cámara, entre los cuadros de excavación I5-J5.

La respuesta física del hueso varía en función de su contenido en humedad en el momento de exposición a la fuente de calor. La temperatura produce fragmentaciones transversales al eje en el hueso fresco y longitudinales en el seco. En este caso se ven reacciones propias de los dos tipos, ya que en el momento de la clausura al menos el $17 \%$ de los cráneos estaban frescos y el 23\% secos (Fig. 13B). Además, abundan las torsiones, estallamientos y fusiones entre huesos amalgamados junto con el sedimento, contribuyendo a la elevada fragmentación de la colección. Por último, todas las coronas de las piezas dentales estallaron al experimentar temperaturas superiores a $300^{\circ} \mathrm{C}$.

Tras la clausura de la tumba los huesos han estado sometidos a diferentes agentes alteradores, como cambios de humedad o la agresión derivada de la propia composición química de los sedimentos y de la acción de las raíces, una de las más perjudiciales al producir disoluciones en forma de malla irregular. Esta alteración se observa mayoritariamente en los huesos de la zona meridional (B).

Todos los huesos del cuerpo humano están representados, incluyendo los del oído y el hueso hioides, con algunas diferencias entre la zona septentrional (A) y la meridional (B). En la primera la representación porcentual es acorde con el NMI documentado, mientras en la zona meridional, donde los restos responden a una selección premeditada, se registra un elevado número de restos de cráneo seguido de huesos largos, porcentajes muy inferiores de costillas y vértebras y prácticamente testimoniales de pelvis y huesos del carpo/tarso. 
A

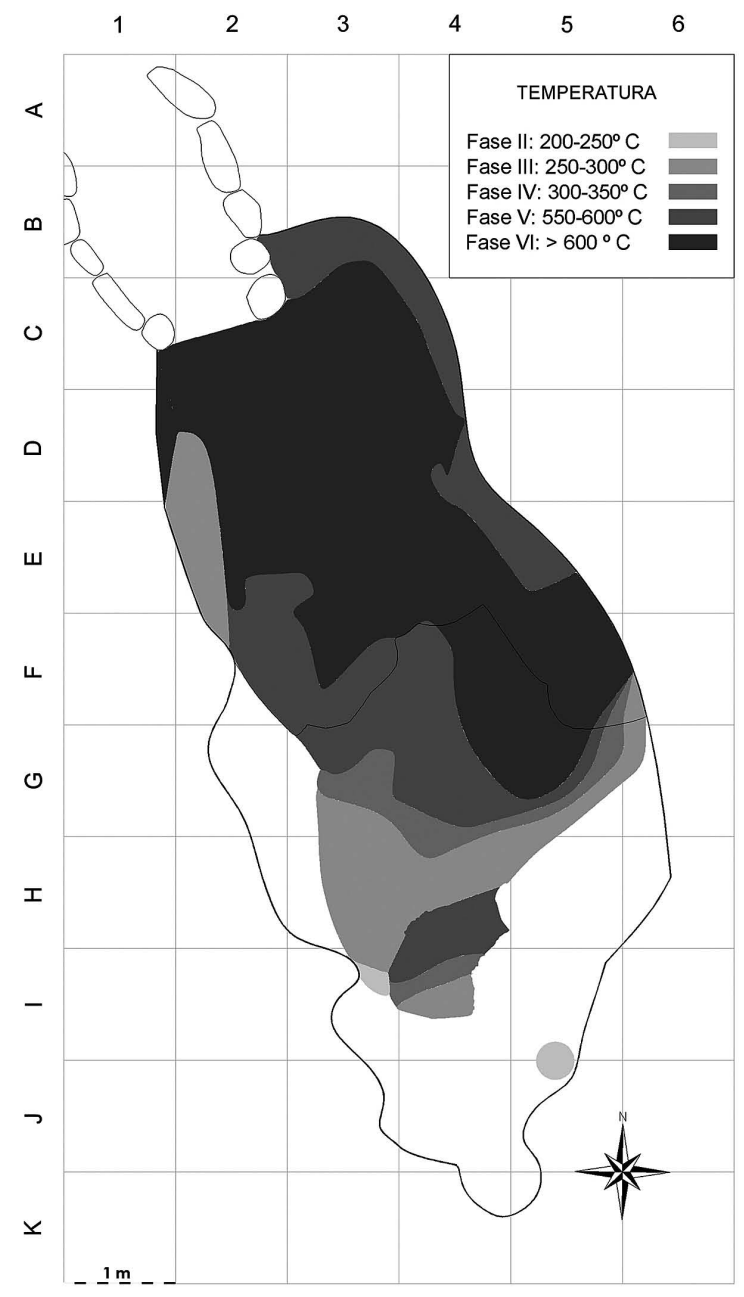

B

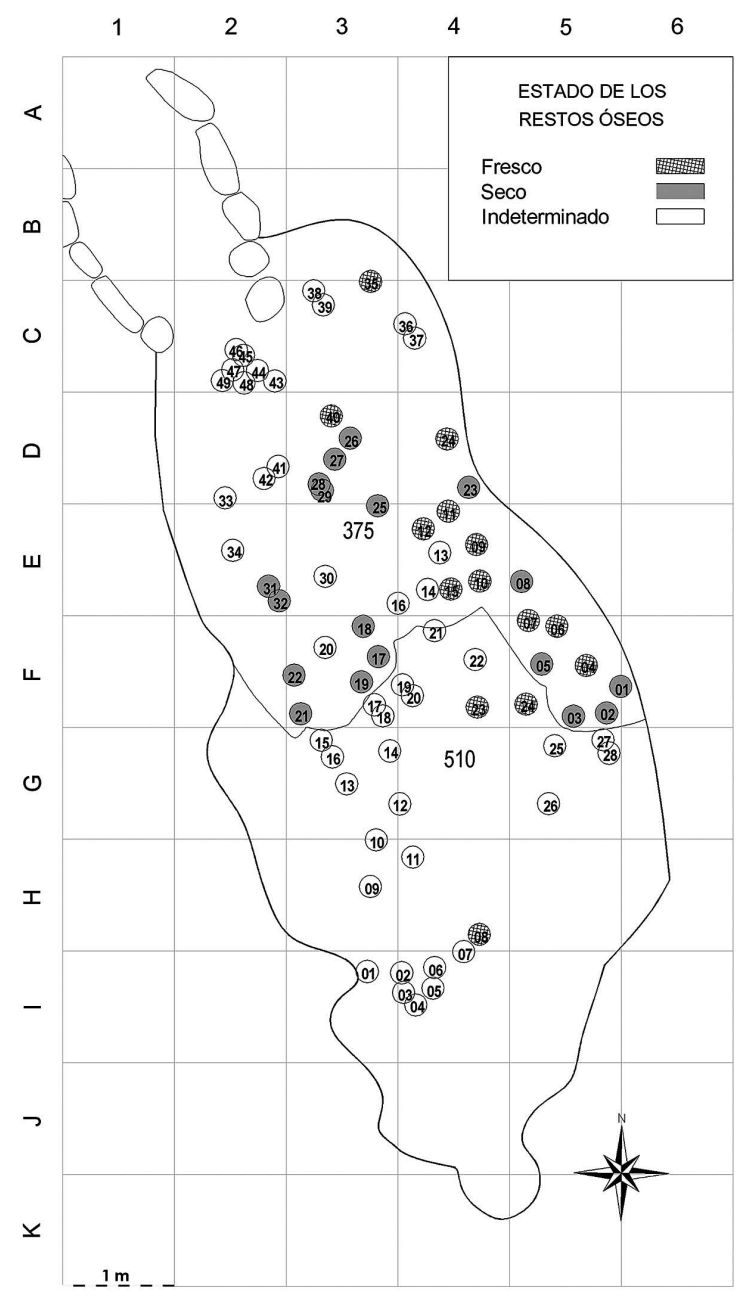

Fig. 13. El Hundido (Monasterio de Rodilla, Burgos): A. temperatura alcanzada en la tumba colectiva durante el proceso de condenación; B. distribución de las calotas identificadas en función de su estado con carácter previo a la condenación de la tumba.

\subsection{Número mínimo de individuos (NMI), edad de muerte, sexo y valores osteométricos}

El NMI ha sido estimado a partir de los huesos largos, de calotas y de porciones petrosas del hueso temporal. En los huesos largos, el NMI se ha estimado a partir de las diáfisis proximales derechas de 44 ulnas, la fracción ósea mejor representada. Únicamente se han contabilizado como calotas las 77 que han podido ser individualizadas con precisión, ya que la fragmentación y dispersión de los restos puede derivar en duplicidades. Sin embargo, el rasgo más clarificador ha sido, sin duda, la por- ción petrosa del hueso temporal con un NMI de 91 (82 porciones derechas y 91 izquierdas).

La edad de los individuos se ha establecido en base a los grupos descritos por Knußmann (1988: 134). La estimación en individuos juveniles, adultos y maduros ha sido realizada sobre 73 de las 77 calotas documentadas, ya que las otras cuatro pertenecen a infantiles. Considerando la práctica total ausencia de conexiones anatómicas, es imposible asociar a un mismo individuo otros restos óseos con factores diagnósticos. Por este motivo, y cuando se pudo, el criterio fundamental de valoración ha sido el grado de obliteración de las suturas craneales. El desgaste de las coronas de 
las piezas dentales asociadas a las calotas tampoco ha podido valorarse ya que, por efecto del calor, solo las conserva el cráneo $\mathrm{n}^{\circ}$ 510-01, situado en una zona que no superó los $250^{\circ} \mathrm{C}$ de temperatura.

En los individuos infantiles han sido valorados otros aspectos. Según las calotas, el NMI es 4: 3 son infantiles I ( $\left.\mathrm{n}^{\mathrm{o}} 375-12,375-36,375-37\right)$ y 1 infantil II ( $n^{\circ}$ 510-26). A partir del número de epífisis proximales de ulnas derechas, se han identificado al menos 8 individuos infantiles: 1 neonato, 5 infantiles I y 2 infantiles II. Con mayor precisión ha podido ser estimada la edad de un conjunto de restos mandibulares y maxilares hallados en la cámara, que aparecieron junto con otros huesos pero sin ninguna conexión. En función del desarrollo de la dentición definitiva, pertenecen a dos individuos de unos 3 y 5 años. Por último, solo un húmero se asocia con certeza a un neonato.

Por lo tanto, la edad de muerte se ha estimado en los 8 individuos infantiles y las 73 calotas de juveniles, adultos y maduros. El resultado de estos 81 individuos se expone en la tabla 1. Se advierte la presencia de todos los grupos de edad, incluidos neonatos, excepto individuos seniles. En general el 15\% de los individuos murieron antes de cumplir los 20 años, alcanzando la madurez solo el $10 \%$. Llama la atención el reducido porcentaje de individuos infantiles. Posiblemente se deba a su peor conservación o a la elección de otro lugar y/o forma de enterramiento, observándose una mayor probabilidad de muerte antes de los 7 años. Por otro lado, la posibilidad de fallecer durante la juventud se puede considerar baja.

\begin{tabular}{|c|c|c|}
\hline Grupo & $\mathbf{N}^{\mathbf{0}}$ de individuos & $\mathbf{( \% )}$ \\
\hline Neonato & 1 & $1,23 \%$ \\
\hline Infantil I (1-6 años) & 5 & $6,17 \%$ \\
\hline Infantil II (7-14 años) & 2 & $2,47 \%$ \\
\hline Juvenil (15-20 años) & 4 & $4,94 \%$ \\
\hline Adulto (21-40 años) & 61 & $75,31 \%$ \\
\hline Maduro (41-60 años) & 8 & $9,88 \%$ \\
\hline Senil (> 61 años) & 0 & $0 \%$ \\
\hline
\end{tabular}

Tab. 1. El Hundido (Monasterio de Rodilla, Burgos). Edad de muerte de los individuos inhumados en la tumba colectiva.
La determinación del sexo en las 73 calotas de individuos de más de 15 años se ha basado en rasgos de dimorfismo sexual. La dificultad de aplicar este procedimiento reside en que prácticamente ninguna de ellas conserva todos los caracteres. Por ello, el número de individuos atribuibles a uno $\mathrm{u}$ otro sexo se ha reducido a 53, siendo relativamente elevadas las atribuciones posibles (26\%). Por porcentajes, se observa la presencia ligeramente inferior de mujeres $(47,16 \%)$, con respecto a la de hombres $(52,83 \%)$.

La esperanza de vida entre las mujeres es inferior a la de los hombres (Tab. 2), posiblemente por los fallecimientos vinculados a procesos de gestación, parto y posparto. No deja de ser significativo que los tres individuos juveniles cuyo sexo ha sido determinable sean mujeres. También cabe atribuir a esta misma causa las pocas mujeres que alcanzaron la edad madura frente al número de varones. Antes de cumplir los 40 años fallecieron el $92 \%$ de las mujeres y el $67,85 \%$ de los hombres.

Los índices osteométricos sólo han podido calcularse en el único hueso completo recuperado: un húmero derecho atribuible a una mujer adulta. Como los huesos se reducen por efecto del calor y el húmero estuvo sometido a una temperatura no inferior a $650^{\circ} \mathrm{C}$, la reducción puede estimarse en un 10-12\% (Wahl 1982: 21). Tomando como base comparativa las medidas e índices del húmero para mujeres calcolíticas andaluzas y de otras regiones europeas de S. A. Jiménez (1), se aprecia que, una vez sumado el $10 \%$ a los valores

\begin{tabular}{|c|c|c|c|c|c|}
\hline & \multicolumn{2}{|c|}{ Hombres } & \multicolumn{2}{c|}{ Mujeres } & \multirow{2}{*}{ Total } \\
\cline { 2 - 5 } & Seguros & Posibles & Seguras & Posibles & \\
\hline Juveniles & 0 & 0 & 3 & 0 & 3 \\
\hline Adultos & 15 & 4 & 14 & 6 & 39 \\
\hline Maduros & 6 & 3 & 1 & 1 & 11 \\
\hline Subtotal & 21 & 7 & 18 & 7 & 53 \\
\hline Total & \multicolumn{2}{|c|}{$28(52,83 \%)$} & $25(47,16 \%)$ & 53 \\
\hline
\end{tabular}

Tab. 2. El Hundido (Monasterio de Rodilla, Burgos). Relación entre sexo y edad de muerte de los individuos inhumados en la tumba colectiva.

(1) Jiménez Brobeil, S.A. 1987: Estudio antropológico de las poblaciones neoliticas y de la Edad del Cobre en la Alta Andalucía. Tesis doctoral inédita, Universidad de Granada. Granada: 434-435. 
iniciales, la longitud $(268 \mathrm{~mm})$ se encuentra entre la mínima y la máxima andaluza (245-311 mm), aunque ligeramente por debajo de la media (278 $\mathrm{mm})$, y considerablemente por debajo de la media europea $(297 \mathrm{~mm})$. Por su parte, los valores referentes al perímetro y al diámetro no alcanzan los mínimos de las poblaciones andaluzas analizadas. Como resultado, el índice diafisario $(68,75)$ está en la media, pero no así el de robustez $(15,29)$. Si el de Andalucía se puede considerar mediano $(18,88)$, aunque inferior al de la media europea $(19,5)$, en El Hundido es bajo. La estatura ha sido estimada en $148,01 \pm 4,45 \mathrm{~cm}$.

\subsection{Paleopatología}

Prácticamente no se han documentado piezas dentales que conserven al menos en parte las coronas, por lo que ha sido imposible constatar casos de caries dental. Sí se observan pérdidas de piezas dentarias ante mortem gracias a la conservación de alvéolos con signos de reabsorción, aunque no parece posible determinar si la causa fue de tipo infeccioso o traumático. Las pérdidas observadas solo se dan en molares y premolares, aunque en algunas mandíbulas afectan a su totalidad existiendo reabsorción alveolar completa.

Entre las enfermedades metabólicas se han identificado dos casos de criba orbitaria en fragmentos de hueso frontal pertenecientes a un individuo adulto y a otro juvenil. Ninguno conserva ambas órbitas, por lo que no es posible determinar si es bilateral. La mayoría de los autores relacionan este tipo de osteoporosis con las anemias, que suelen considerarse una de las primeras manifestaciones de la enfermedad y se documentan con mayor frecuencia en individuos muy jóvenes (Isidro y Malgosa 2003: 69, 145). También ha sido reconocido un proceso de osteólisis en el frontal y en el parietal de un cráneo, tal vez relacionado con una afección metabólica. Se trata de un individuo adulto, quizás una mujer, de 25-35 años de edad de muerte.

El estudio de los marcadores de actividad o de estrés ocupacional ha aportado interesante información sobre el estilo de la vida. Se manifiestan frecuentemente en forma de enthesopatías que, por su fragilidad y pequeño tamaño, en El Hundido pueden haber desaparecido debido a las varias alteraciones a las que han sido expuestos los restos óseos. Aún así, han sido identificados varios marcadores, en su mayoría en las extremidades superiores, como en un húmero izquierdo femenino con elevado desarrollo de la tuberosidad deltoidea acompañado de enthesopatías. El músculo deltoides hace funciones de aproximación, separación, retroversión y rotación medial y lateral, a la par que soporta el peso del miembro superior. En este caso, la aparición de enthesofitos se debe al sometimiento habitual del brazo a un esfuerzo físico elevado. También se observan altos desarrollos de la tuberosidad bicipital del radio, con o sin formación de enthesofitos. $\mathrm{La}$ tuberosidad bicipital es el punto de inserción del músculo bíceps braquial, principal responsable de la flexión del codo, por lo que los marcadores descritos suelen estar asociados al transporte de cargas pesadas con los codos flexionados (Isidro y Malgosa 2003: 229).

Son reseñables los abundantes osteofitos en la inserción muscular del tendón de Aquiles de un calcáneo, en relación con una actividad física importante vinculada a recorrer largas distancias por lugares agrestes. En poblaciones medievales castellanas este marcador se ha relacionado con la actividad pastoril (Galera y Garralda 1993: 247). También existen enthesopatías en la superficie ventral de una rótula y en varias falanges de carpo y tarso. Un fragmento de costilla con osteoartritis en las superficies articulares vertebrales es un caso de patología asociada a la reiteración de movimientos intensos de elevación de objetos pesados. Algunos autores la han identificado en mujeres que acarrean a sus hijos a la espalda (Isidro y Malgosa 2003: 228).

Por último, la presencia de nódulos de Schmörl en algunas vértebras suele obedecer a una patología traumática relacionada con esfuerzos físicos, donde el colapso superior e inferior origina herniaciones intervertebrales del disco. A parte del estrés mecánico producido por cargas axiales, su aparición puede deberse a otras causas de tipo traumático, infeccioso o metabólico, aunque hay autores que defienden que el reiterado levantamiento y soporte de cargas pesadas es la principal actividad que induce la aparición de esta lesión (2). En un

(2) Casas, M. J. 1997: Principales marcadores óseos macroscópicos de estrés físico en poblaciones humanas: su validez como indicadores de gestos repetitivos. Tesis doctoral inédita, Universidad Complutense de Madrid, Madrid. 
caso, las lesiones están acompañadas del hundimiento de discos vertebrales y de artrosis.

Un fragmento de parietal procedente del corredor muestra lesiones relacionadas con el ambiente físico y cultural. Presenta una perforación de forma triangular, de $0,52 \mathrm{~mm} \times 0,22 \mathrm{~mm}$, situada entre el borde occipital y el temporal, a pocos milímetros del asterion. A juzgar por su forma y dimensión, podría tratarse del impacto de una punta de flecha. Como el hueso está muy afectado por las altas temperaturas y por la acción de las raíces, no se puede confirmar con total seguridad los aparentes signos de osteólisis, que indicarían que la lesión se produjo pre mortem y no peri mortem.

También ha sido identificada una rótula izquierda a la que le falta buena parte del polo supero externo, circunstancia compatible con una rótula bipartita tipo III según la clasificación de Saupe (1943), el tipo más frecuente. Sin embargo, es posible que la pérdida de la porción ósea se deba a una fractura. Entonces, la presencia de una espícula visible en el borde lateral podría formar parte del tejido óseo neoformado en el proceso de consolidación o bien indicar una afección artrósica o enthesopática del ligamento rotuliano.

La artrosis se identifica en varios huesos a nivel vertebral, en las extremidades superiores y en la articulación coxo-femoral. Como patología vertebral destaca un conjunto de cervicales dorsales y lumbares halladas sin conexión anatómica, pero pertenecientes al mismo individuo, que presentan sindesmófitos proyectados a las vértebras vecinas, aunque sin fusión entre ellas, asociado a espondilitis. En las articulaciones de las extremidades superiores han sido identificadas artrosis a nivel de la circunferencia articular en dos ulnas derechas, en la articulación radiocubital distal. A nivel de la articulación coxo-femoral cabe mencionar procesos artrósicos, identificados en el borde del acetábulo de un fragmento de pelvis y en un cóndilo femoral.

Por último, se constatan variaciones genéticas que no suelen cursar sintomatología en los individuos que las padecen y suelen pasar inadvertidas a lo largo de la vida. Además del posible caso de rótula bipartita ya citado, cabe mencionar la presencia de proceso supracondíleo en un húmero izquierdo, una variación que aparece con mayor frecuencia en las poblaciones prehistóricas (Campillo y Subirá 2004: 140) y un caso de tercer trocánter en el fémur izquierdo de un individuo juvenil.

\section{CONCLUSIONES}

\subsection{La tumba colectiva de El Hundido en su contexto regional}

Las manifestaciones funerarias documentadas en la tumba colectiva El Hundido permiten confirmar una vez más las claras conexiones culturales entre esta comarca y la cuenca alta y media del Valle del Ebro, aspecto constatado en las tumbas campaniformes intrusivas construidas quinientos años después (Alonso 2013) y en dos tumbas neolíticas individuales en fosa documentadas en las proximidades (Alonso y Jiménez e.p.). En estas relaciones culturales jugará un papel fundamental el corredor natural junto al que se localiza el yacimiento, de trascendental relevancia histórica en la conexión de las cuencas altas del Ebro y del Duero. Esta conexión desde el Pirineo occidental, cruza el extremo del paso natural del Sistema Ibérico, con el desfiladero de Pancorbo como hito reseñable y, por el otro lado, remonta el curso del Ebro. Ya en época histórica estas mismas rutas serán la base del trazado de las vías romanas I y XXXIV, ambas confluyentes en la cercana localidad de Briviesca, y también de los dos principales itinerarios del Camino de Santiago. Gracias a su estratégica localización, el yacimiento mantiene importantes similitudes desde el punto de vista ritual y de la cultura material con otros de las provincias de La Rioja, Navarra, Álava y Soria, ya que su situación fronteriza en el límite septentrional de la Meseta propició la introducción de las novedades culturales de las gentes que utilizaron el Valle del Ebro como vía de tránsito y difusión.

La tumba colectiva de El Hundido se enmarca en la forma de enterramiento utilizada durante el Neolítico Final-Calcolítico en la Península Ibérica y en otros ámbitos europeos occidentales, abandonada a finales de este último periodo en beneficio del enterramiento individual. En esta afirmación genérica cabe un amplio abanico de matices dado el complejo repertorio de manifestaciones funerarias conocidas (Fabián 1995: 105 y ss.), pero grosso modo pueden clasificarse en tumbas monumentales, dolménicas o no, y cuevas sepulcrales. El Hundido viene a ser un ejemplo de tumba monumental colectiva de carácter no megalítico clausurada mediante fuego. El carácter colectivo es su seña de identidad, necesario en el momento de 
su construcción y clausura, en forma de esfuerzo conjunto por parte de los miembros de la comunidad y presente en las diferentes fases rituales.

Los eventos de clausura más cercanos de tumbas monumentales asociados en mayor o menor medida al fuego han sido constatados en el conjunto soriano del Valle de Ambrona (Rojo et al. 2005), en El Miradero de Villanueva de los Caballeros, en Valladolid (Delibes et al. 1987), en los yacimientos Portillo de los Ladrones, Collado Palomero I y Collado del Mallo, todos en la riojana comarca de Cameros (López de Calle 2002), o en el dolmen alavés de Aizkomendi (Narvarte 2005: 72). En la provincia de Burgos cabe citar Los Morcales de Barbadillo del Mercado (Rojo et al. 2002), El Rebolledo de Sedano (Delibes y Rojo 1997) y la tumba de Villayerno-Morquillas (Arnáiz et al. 1997). La presencia de cal o sílice vitrificada sólo ha sido atestiguada en el conjunto soriano, en El Mirandero y en Portillo de los Ladrones.

Por sus características constructivas, el ejemplo más próximo a El Hundido es el riojano de Portillo de los Ladrones, en Viguera. La mayor similitud reside en su carácter semirupestre: en el caso riojano la cámara se habilitó mediante la excavación de una fosa en el suelo rocoso (López 2002: 242), mientras que en El Hundido se partió de una grieta natural en el terreno que a su vez fue retallada, de manera que en los dos casos quedaba bajo la cota de la superficie. En ambos monumentos la cubierta parece que fue realizada a partir de materia vegetal, un aspecto coincidente con la tumba soriana de La Tarayuela (Rojo et al. 2005: 232). En el caso riojano el calor vitrificó la sílice (Narvarte 2005: 221), y en el soriano se formó una costra parcial de cal. Ambas reacciones químicas han sido constatadas en El Hundido, cuya calcificación parcial debe atribuirse a la ausencia de cubierta pétrea como parece constatado en la tumba soriana (Rojo et al. 2005: 193). Estos dos ejemplos, próximos a nuestro yacimiento en cuanto a tipología estructural y condenación, están encuadrados en un contexto cultural neolítico, en el segundo tercio del IV milenio en fechas calibradas para el caso de La Tarayuela (Rojo et al. 2005: 195) y sin dataciones absolutas en Portillo de los Ladrones. Por último, la tumba colectiva condenada por fuego más próxima, en esta ocasión calcolítica, es la de Villayerno-Morquillas (Arnáiz et al. 1997), a tan solo $15 \mathrm{~km}$ de distancia y en el ámbito de influencia del corredor natural mencionado. Es de lamentar que, por su mala conservación, durante su excavación fue imposible determinar las características estructurales y no cuenta con dataciones absolutas.

La prueba de $\mathrm{C}^{14}$ realizada en El Hundido, sobre una muestra de sedimento carbonoso recogida en la cámara principal, proporciona una datación convencional $4293 \pm 52$ BP (CSIC-1984), que refiere un rango 3030-2859 cal $\mathrm{BC}(84,7 \%)$ calibrado a $2 \sigma$ (Reimer et al. 2004) para la condenación del monumento (3). Según las dataciones aportadas por la cueva segoviana de La Vaquera (Estremera 2003: 188), el inicio del Calcolítico se sitúa entre el 3300 y el 2800 en fechas calibradas, no muy alejadas de las propuestas por F. Fabián (2006: 447) (3000-2800 cal BC), por lo que la condenación de la tumba estaría enmarcada culturalmente en momentos aún iniciales del Calcolítico. Sin duda, los primeros enterramientos debieron tener lugar tiempo atrás, quizás en el Neolítico Final, como parecen estar indicando ciertos materiales arqueológicos. Al mismo tiempo, al proceder la muestra de la madera utilizada en la fase de clausura y no ser de vida corta, podría estar retrasando la cronología de manera artificial en función de la edad del combustible. Ello implicaría una condenación del monumento en fechas más avanzadas.

\subsection{El rito funerario como símbolo de colectividad}

El Hundido fue un monumento identificable en el paisaje gracias a su destacada posición en un borde de páramo, símbolo del predominio del sentimiento de pertenencia al grupo frente al individual. De hecho, la mezcla de los restos óseos serviría para reafirmar la identidad colectiva. La destrucción del sepulcro debe ser entendida como parte de un complejo ritual que incluyó la práctica de depósitos selectivos (agrupamiento de cráneos y haces de huesos largos) fuera de la cámara principal. La parte del ritual, durante la que se espera la descomposición de los cuerpos para recibir

(3) Programa de calibración: OxCal v 3.10, Universidad de Oxford, Curva de calibración: INTCAL04 (24,000-0 cal BP). Lamentablemente otra muestra realizada sobre restos óseos no contenía fracción de colágeno 
sepultura definitiva, ha estado muy extendida en diversas culturas desde la Prehistoria hasta la actualidad. Tiene su explicación en el entendimiento del funeral como un rito de paso, que requiere esperar hasta que desaparezca la carne para que el alma abandone definitivamente el mundo de los vivos y viaje al más allá (Metcalf y Huntington 1991: 84 y ss). En los megalitos de La Lora burgalesa han sido identificadas algunas de estas prácticas, destacando el agrupamiento de cráneos y huesos largos documentado en el dolmen de Las Arnillas (Delibes et al. 1993: 58). Las características estructurales y rituales de El Hundido tienen en este caso un singular valor.

El ritual culminaría con la condenación de la estructura mediante cremación, acto en el que se vería implicada gran parte de la comunidad que debió avivar el fuego durante varios días, completado con el depósito de ofrendas colectivas. Estas han llegado a nosotros como recipientes cerámicos situados fuera de la cámara y sin asociación a individuos concretos, una nueva muestra de la preponderancia de lo colectivo.

La proporción similar de ambos sexos y la presencia de todos los grupos de edad son indicativas de que, al menos, muchos de los miembros integrantes de la comunidad debieron ser enterrados en este lugar. El número mínimo de individuos constatados y el carácter acumulativo de las inhumaciones, que determina una formación mediante eventos sucesivos muy presente en este tipo de ritual (Schwarz 2013), indican que el proceso debió prolongarse durante varias generaciones. En base a la aceptación general del carácter transterminante de las poblaciones calcolíticas en la región, lo lógico es suponer que no todos sus miembros fallecieron en este lugar. La utilización del sepulcro debió tener un arco temporal superior condicionado por entierros puntuales durante la permanencia del grupo en las cercanías. Sin duda, el lugar de enterramiento cambiaría en función de la movilidad de sus miembros. Ello dota de especial relevancia a la tumba de VillayernoMorquillas (Arnáiz et al. 1997), que cumpliría la misma finalidad a $15 \mathrm{~km}$ de distancia de El Hundido.

Precisamente, este largo uso puede explicar la presencia de ciertos materiales arqueológicos considerados frecuentemente ajenos al Calcolítico, que sirven para retomar el capítulo del en- cuadre cronológico de la tumba. Entre ellos están dos trapecios, uno de ellos con la base menor retocada, asociados a la fase de utilización y recuperados en el corredor y en la cámara. Atendiendo al estudio de este tipo de materiales en las tumbas del Valle de Ambrona (Alegre 2005: 301), los geométricos trapezoidales son las formas dominantes del Neolítico Final. Tal afirmación permitiría situar el primer uso de la tumba en ese momento cultural, cuando los geométricos, que conviven con puntas de flecha con retoque plano, también representadas en el yacimiento, son ya una tipología en retroceso. Ello explicaría su discreta presencia y haría más que probable la posibilidad de que la tumba tuviera su origen en el Neolítico Final.

\section{AGRADECIMIENTOS}

La excavación arqueológica en El Hundido fue financiada por GENESA-NEOENERGÍA (EDP Renovàveis).

\section{BIBLIOGRAFÍA}

Alegre Frandovínez, I. 2005: "Estudio del conjunto de los materiales líticos tallados de las tumbas del valle de Ambrona (Soria)". En M. A. Rojo, M. Kunst, R. Garrido, I. García y G. Morán: Un desafío a la eternidad: tumbas monumentales del Valle de Ambrona. Junta de Castilla y León. Valladolid: 299-306.

Alonso Fernández, C. 2013: "Las tumbas campaniformes del monumento funerario 'El Hundido' (Monasterio de Rodilla, Burgos)". Munibe (Arqueología-Antropología) 62: 89-103.

Alonso Fernández, C. y Jiménez Echevarría, J. e.p.: "El Neolítico en el corredor Alto Ebro-Alto Duero: dos hallazgos funerarios del Neolítico Antiguo y Reciente en Monasterio de Rodilla (Burgos)". Actas del $5^{\circ}$ Congresso do Neolítico Peninsular (Lisboa 2011): 504-510. Lisboa.

Arnáiz Alonso, M. A.; Pascual Blanco, S y Rojo Sanz, A. V. 1997: "Los semejantes y los otros: la sepultura múltiple simultánea de Villayerno-Morquillas, Burgos. Nota preliminar". Boletín del Seminario de Arte y Arqueología 63: 49-69.

Campillo, D. y Subirá, M.E. 2004: Antropología física para arqueólogos. Ariel. Barcelona.

Delibes, G.; Alonso, M. y Galván, R. 1986: “El Miradero: un enterramiento colectivo tardoneolítico 
de Villanueva de los Caballeros (Valladolid)". D. Trujillo (ed.): Estudios en Homenaje al Dr. Antonio Beltrán Martínez. Universidad de Zaragoza. Zaragoza: 227-236.

Delibes, G. y Rojo, M. 1997: “C14 y secuencia megalítica en la Lora burgalesa: acotaciones a la problemática de las dataciones absolutas referentes a yacimientos dolménicos". Actas do Coloquio Internacional O Neolítico Atlántico e as orixes do megalistismo (Santiago de Compostela 1996): 391-414. Santiago de Compostela.

Delibes, G.; Rojo, M. y Represa, J. I. 1993: Dólmenes de La Lora, Burgos. Junta de Castilla y León. Valladolid.

Estremera Portela, M. S. 2003: Primeros agricultores y ganaderos en la Meseta Norte: el Neolítico de la Cueva de la Vaquera (Torreiglesias, Segovia). Arqueología en Castilla y León 11, Junta de Castilla y León. Valladolid.

Etxeberría Gabilondo, F. 1994: "Aspectos macroscópicos del hueso sometido a fuego. Revisión de las cremaciones descritas en el País Vasco desde la Arqueología". Munibe (Antropología-Arqueología) 46: 111-116.

Isidro Llorens, A. y Malgosa Morera, A. (eds.) 2003: Paleopatología, la enfermedad no escrita. Masson, Barcelona.

Fabián García, J. F. 1995: El aspecto funerario durante el Calcolítico y los inicios de la Edad de Bronce en la Meseta Norte. Universidad de Salamanca. Salamanca.

Fabián García, J. F. 2006: El IV y III milenio AC en el Valle Amblés (Ávila). Arqueología en Castilla y León 5, Junta de Castilla y León. Valladolid.

Galera, V. y Garralda, M. D. 1993: "Enthesopathies in a spanish medieval population: anthropological, epidemiological and ethnohistorical aspects". International Journal of Anthropology 8, 4: 247-258.

Joussaume, R. y Tarrête, J. 2010: "La fin du Néolithique dans la moitié nord de la France". En J. Clottes (ed.): La France préhistorique: un essai d'histoire. Gallimard. París: 337-360.

Knußmann, R. (ed.) 1988: Anthropologie. Handbuch der vergleichen den Biologie des Menschen $\mathrm{I} / 1$. Ficher. Stuttgart.

López de Calle, C. 2002: "Huesos quemados, hogares y sepulcros incendiados. El fuego en los sepulcros monumentales de Cameros". En M. A. Rojo y M. Kunst (eds.): Sobre el significado del fuego en los rituales funerarios del Neolítico, Studia Archaeologica 91, Universidad de Valladolid. Valladolid: 233-252.
Meller, H. 2013: 3300 BC. Mysteriöse Steinzeittote und ihre Welt. Landesmuseum für Vorgeschichte, Nünnerich-Asmus Velag \& Media. Mainz.

Metcalf, P. y Huntinton, R.1991: Celebrations of Death: The Anthropology of mortuary ritual. Cambridge University Press. Cambridge.

Narvarte Sanz, N. 2005: Gestión funeraria dolménica en la cuenca alta y media del Ebro: fases de ocupación y clausura. Historia-Arqueología 16, Instituto de Estudios Riojanos. Logroño.

Reimer, P. J.; Baillie, M. G. L.; Bard, E.; Bayliss, A.; Beck, J. W.; Bertrand, Ch. J. H.; Blackwell, P. G.; Buck; C. E.; Burr, G. S.; Cutler, K. B.; Damon, P. E.; Edwards, R. L.; Fairbanks, R. G.; Friedrich, M.; Guilderson, Th. P.; Hogg, A. G.; Hughen, K. A.; Kromer, B.; McCormac, G.; Manning, S.; Ramsey, Ch. B.; Reimer, R. W.; Remmele, S.; Southon, J. R.; Stuiver, M.; Talamo, S.; Taylor, F. W.; van der Plicht, J.; Weyhenmeyer, C. E. 2004: "INTCAL04 terrestrial radiocarbon age calibration, 0-26 CAL KYR BP”. Radiocarbon 46, 3: 1029-1058

Rojo, M. A. y Kunst, M. (eds.) 2002: Sobre el significado del fuego en los rituales funerarios del Neolítico, Studia Archaeologica 91. Universidad de Valladolid. Valladolid.

Rojo, M. A.; Kunst, M.; Garrido, R.; García, I. y Morán, G. 2005: Un desafio a la eternidad: tumbas monumentales del Valle de Ambrona. Junta de Castilla y León. Valladolid.

Rojo, M.A.; Kunst, M.y Palomino, A.L. 2002: "El fuego como procedimiento de clausura en tres tumbas monumentales de la Submeseta Norte". En M. A. Rojo y M. Kunst (eds.): Sobre el significado del fuego en los rituales funerarios del Neolítico, Studia Archaeologica 91: 21-38.

Saupe, E. 1943: "Primäre knochenmarkseiterung der kniescheibe". Deusche Zeitschrift für Chirurgie 258: 386-392.

Schwarz, R. 2013: "Mehrstufige Bestattungssitten". En H. Meller (ed.): 3300 BC. Mysteriöse Steinzeittote und ihre Welt. Landesmuseum für Vorgeschichte, Nünnerich-Asmus Velag \& Media. Mainz: 338-341.

Terradas, X. y Gibaja, J.F. 2001: "El tratamiento térmico en la producción lítica: el ejemplo del Neolítico Medio catalán". CYPSELA 13: 31-58.

Wahl, J. 1982: "Leichenbrandutersuchungen. Ein Überblick über die Bearbeitungs-und Aussagemöglichkeiten von Brandgräbern". Prähistorische Zeitschrift 57: 1-125. 